\title{
Advanced Production Surface Preparation Technology Development for Ultra-High Pressure Diesel Injection
}

Final Technical Report

DOE Award No. DE-EE0003452

Project Period: 8/16/10 - 1/31/12

Issued Date: April 30, 2012

\author{
Caterpillar Inc. \\ Product Development \& Global Technology \\ 14009 Old Galena Rd., TC-A \\ Mossville, IL 61552-7547
}

Project Director/Principal Investigator: Dr. Marion B. (Bill) Grant,

Telephone: 309.578.8580,

E-mail: Grant Marion B@cat.com

Business Contact: Barbara Shane,

Telephone: 309.494 .7101

Shane_Barabara_K@cat.com

US DOE Technology Manager: Steven Sikirica,

Telephone: 202.586 .5041

Stephen.sikirica@hq.doe.gov

US DOE Project Officer: Dibyajyoti (Debo) Aichbhaumik, Ph.D, PMP

Telephone: 720.356 .1423

Debo.aichbhaumik@go.doe.gov

US DOE Contract Specialist: Christina Kouch,

Telephone: 720.356 .1674

Christina.kouch@go.doe.gov 


\section{Acknowledgment, Disclaimer and Document Availability}

This report is based upon work supported by the U. S. Department of Energy, under Award No. DE-EE0003452.

This report was prepared as an account of work sponsored by an agency of the United States Government. Neither the United States Government, nor any agency thereof, nor any of their employees, makes any warranty, express or implied, or assumes any legal liability or responsibility for the accuracy, completeness, or usefulness of any information, apparatus, product, or process disclosed, or represents that its use would not infringe privately owned rights. Reference herein to any specific commercial product, process, or service by trade name, trademark, manufacturer, or otherwise does not necessarily constitute or imply its endorsement, recommendation, or favoring by the United States Government or any agency thereof. Any findings, opinions, and conclusions or recommendations expressed in this report are those of the authors and do not necessarily reflect those of the United States Government or any agency thereof.

Reports are available free via the U.S. Department of Energy (DOE) Information Bridge Website: http://www.osti.gov/bridge

Reports are available to DOE employees, DOE contractors, Energy Technology Data Exchange (ETDE) representatives, and Informational Nuclear Information System (INIS) representatives from the following source:

Office of Scientific and Technical Information

P.O. Box 62

Oak Ridge, TN 37831

Tel: (865) 576-8401

FAX: (865) 576-5728

E-mail: reports@osti.gov

Website: http://www.osti.gov/contract.html 
1. List of Acronyms Used 4

2. List of Figures 5

3. List of Tables 5

4. Abstract - Executive Summary 6

$\begin{array}{ll}\text { 5. Introduction - Project Objective } & 7\end{array}$

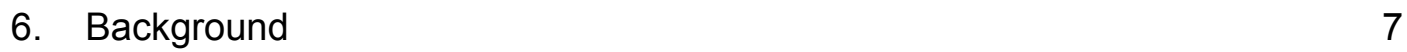

7. Results and Discussion 8

7a. Compressive Residual Stress Insertion Process Development 8

7b. Production Precision Profiling Process Development 20

7c. Computed Tomography X-ray Dimensional Control Development 30

8. Benefits Assessment 33

9. Commercialization - Potential Markets $\quad 35$

10. Conclusions and Recommendations - for this project 36

11. References 37 


\section{LIST OF ACRONYMS}

Automotive Industry Action Group

Average peak-to-valley surface roughness

AIAG

Brake Horsepower

$\mathrm{Rz}$

Brake specific fuel consumption

BHP

British Thermal Unit

BSFC

Caterpillar Fuel Systems - Product Development

BTU

Caterpillar fuel system being considered for technology implementation

Compressive Residual Stress

FS-PD

Computed Tomography

CR600

CRS

Computerized measuring microscope

CT

Cooled Exhaust Gas Recirculation

Mahr MarVS222

Diesel Particulate Trap

CEGR

DPT

Gage repeatability and reproducibility test

GR\&R

GigaPascal

$\mathrm{GPa}$

Green House Gas (emissions)

GHG

Highest peak-to-valley waviness

Wt

The International Academy for Production Engineering

CIRP

International Machine Tool Show

IMTS

Measurement Systems Analysis

MSA

MegaPascal

$\mathrm{MPa}$

Megawatts

MW

National Biodiesel Board

NBB

Nitrous Oxides

NOx

Outer Diameter

OD

Process capability (width) regardless of targeting in the tolerance

$\mathrm{Cp}$

Process capability including distribution mean distance to tolerance limits Cpk

Selective Catalytic Reduction

Statement of Project Objectives

Technical Readiness Level

SCR

Ultra-High Pressure Diesel Injection

SOPO

Ultra High Pressure Common Rail

Unites States Department of Agriculture

United States Environmental Protection Agency

TRL

UHIP

UHPCR

USDA

US EPA or EPA 


\section{LIST OF FIGURES}

Figure 1. First 15 tips with CRS generation: five with one pulse, five with tow and five with three. The vertical axis is in normalized surface movement units. Note some show surface movement apparently in the wrong (tensile) direction.

Figure 2. Measured surface movement in 43 tips. Target movement is to be greater than the first grid line above the horizontal axis. Note some tips that measured with reverse movement.

Figure 3. Surface movement from just above the sack and into the bottom of the ground check seat. Note that the ground check seat appears to receive tensile stress from the CRS generation process

Figure 4. Flow results on 40 tips from before to after the CRS generation. This showed that tip flow does not change significantly from before to after the CRS generation process.

Figure 5. The final 40 tips to have CRS generation, result of before and after CT X-ray. Note that none of these tips showed the reverse direction of surface movement, proving that careful calibration and metrology methodology was effective to eliminate errors.

Figure 6. The molding and digital optical comparator capability development by the Precision Profiling process supplier for this project.

Figure 7. A one-to-one scale of a typical profile showing before the precision profiling process in light blue and after in red, show how the process leaves no witness of the prior profile and leaves a nicely blended radius into adjacent geometries.

Figure 8. Typical 2D profile information from the CT X-ray measurement of Precision Profiled sac regions of tips. Boxed values are the results of least squares fitting. The black profile is from before the Precision Profiling. The red profile is from after.

\section{LIST OF TABLES}

Table 1. Synopsis of CT X-ray least squares results from 2D profiles.

Table 2. Estimated fuel savings from accumulated Tier 4 Final engines in operation

Table 3. Average annual hours of engine use

Table 4. National Biodiesel Board US production-volume estimates 


\section{ABSTRACT - EXECUTIVE SUMMARY}

An Ultra High Injection Pressure UHIP fueling method has been demonstrated by Caterpillar Fuel Systems - Product Development, demonstrating that they have the design knowledge to deliver United States (US) Environment Protection Agency (EPA) Tier 4 Final diesel engine emission performance with greatly reduced emissions handling components on the engine. For example, they could reach Tier 4 Final levels without NOx reduction after-treatment and with only a through-flow $50 \%$ effective diesel particulate trap (DPT), or with no particulate trap or cooled exhaust gas recirculation (CEGR) and high efficiency nitrous oxides (NOx) reduction after-treatment. They have shown capability with these engine configurations through multiple multi-cylinder engine tests of an Ultra High Pressure Common Rail (UHPCR) fuel system with higher than traditional levels of CEGR, and with an advanced injector nozzle design. The system delivers better atomization of the fuel, for more complete burn to greatly reduce diesel particulates, while CEGR or high efficiency NOx reduction after-treatment handles the NOx. With the reduced back pressure of a traditional DPT, and with the more complete fuel burn, the system provides reduced levels of fuel consumption by $2.4 \%$ for similar delivery of torque and horsepower over the best Tier 4 Interim levels of fuel consumption in the diesel power industry.

The challenge is to manufacture the components in high volume production that can withstand the required higher pressure injection. Production processes must be developed to: 1.Increase the toughness of the injector steel to withstand the UHIP pulsations and 2. Generate near perfect form and finish in the sub-millimeter size geometries within the injector.

This project had two major objectives. The first objective was to explore and develop methods for imparting a high target of compressive residual stress (CRS) to key surfaces of the fuel system to increase the toughness of the steel, and demonstrate the feasibility of further refinement of these methods. The second objective was to explore and develop methods for imparting near perfect, durable geometry to these same feature surfaces to withstand the pulsating UHIP diesel injection without fatigue failure, through the expected life of the fuel system's components (10,000 hours for the pump and common rail, 5000 hours for the injector). The potential to Caterpillar of this fueling approach and the overall emissions reduction system is the cost savings of the fuel, the cost savings of not requiring a full emissions module and other emissions hardware, and the enabling of the use of biodiesel fuel due to the reduced dependency on after-treatment.

A proprietary production CRS generating process was developed to treat the interior of the sactype injector nozzle tip region (particularly for the sac region). Ninety-five tips passed fatigue testing with no failures assignable to treated surfaces or materials. It was determined that the CRS method does not weaken the tip internal seat area. Caterpillar Fuel Systems - Product Development accepts that the CRS method initial production technical readiness level (TRL4) has been established. Validation of the sac geometry after CRS and Precision Profiling has been capably measured using Computed Tomography (CT) X-ray results. A precision profiling process for injector seat and sac regions has been shown to be promising but not yet fully confirmed that it can achieve form and geometry to well under an aggressively small micron peak-to-valley and that there are no surface flaws that approach an even tighter micron peak-tovalley tolerance. A method to gage CRS levels in production was not yet accomplished, but it is believed that monitoring process parameters call be used to guarantee quality. It is planned to transfer results to production and engineering and purchase machines to further develop and move the process towards production. The system is targeted towards the high-power diesel 
electric power generators and high-power diesel marine power generators, with displacement from 20 liters to 80 liters and with power from 800 brake horsepower (BHP) to $3200 \mathrm{BHP}(0.6$ megawatts to 2.4 megawatts). However, with market adoption, this system has the potential to meet EPA exhaust standards for all diesel engines nine liters and up, or 300BHP to 3200BHP (0.2megawatts to 2.4 megawatts). If achieved, this would include all of Caterpillar's engines except for the smallest and largest engine series.

A conservative estimate of expected energy savings from improved fuel economy alone in Caterpillar engines using this approach is above 250 trillion British Thermal Units per year (BTU/yr) by 2020. Further fuel savings will be realized due to the reduced weight of the reduced emissions hardware on Caterpillar engines and machines. The enabling of the use of biodiesel and other renewable fuels will accelerate the utilization of such fuels, to reduce US dependence on foreign oil and to create above 50,000 new US jobs by 2020 , pushing estimated use to two to three billion gallons by that time frame. Biodiesel has been shown to actually REDUCE $\mathrm{CO}_{2}$ in the air by United States Department of Energy (USDOE) Reports, so this thrust will make major impact toward US contribution to reduction of green house gas (GHG) emissions in the world.

\section{INTRODUCTION - PROJECT OBJECTIVE:}

In order to decrease diesel engine emissions and meet US EPA regulations with minimized after-treatment, this project has two major objectives to enable higher engine injection pressure:

1. To increase the toughness of the steel to withstand the ultra-high, pulsing injection pressures.

2. To generate, at near perfect form and dimension, the required, well blended geometries that

see ultra-high pulsing fuel pressure.

With this approach, there is potential with sufficiently high injection pressure and tight control to reach EPA Tier 4 Final Exhaust NOx for 2014 with much less extensive after-treatment than is planned to be necessary for more traditional high pressure injection. Savings with less extensive after-treatment would be:

1. Better fuel economy with greater power density due to the reduced exhaust back pressure.

2. The cost savings to the manufacturer and the customer for the simpler after-treatment,

3. Lower mass of simpler after-treatment on a tractor or vehicle, requiring less fuel to move.

4. Enabling biodiesel fuel use, due to reduced dependency on extensive after-treatment.

\section{BACKGROUND:}

\section{A. Reasons for the Project:}

1. Caterpillar Fuel Systems - Product Development has demonstrated with multiple 6 cylinder engine tests the ability to deliver US EPA Tier 4 Final diesel engine emissions without NOx reduction after-treatment with only a $50 \%$ effective through-flow diesel particulate trap (DPT).

2. An Ultra High Pressure Common Rail (UHPCR) fuel system was used with high levels of Cooled Exhaust Gas Recirculation (CEGR), and with an advanced injector, resulting in:

a. Better atomization of the fuel to reduce diesel particulates by $50 \%$,

b. Cooler combustion from the high levels of CEGR reduces NOx by $80 \%$.

3. With the reduced DPT back pressure and more complete fuel burn, the system provides reduced levels of fuel consumption by $2.4 \%$ for similar delivery of torque and horsepower over the best Tier 4 Interim fuel consumption levels using a diesel particulate trap (DPT) and selective catalytic reduction (SCR) of NOx. 
4. The potential to Caterpillar of this fueling approach and the overall emissions reduction system is the cost savings of the fuel, the cost savings of not requiring a full emissions module, and enabling use of biodiesel fuel due to reduced after-treatment dependency.

\section{B. Technical and Commercial Issues being addressed:}

1. The drawback to this demonstration was that several pumps, injectors and common rails were blown during the course of the testing after only 100 to 200 hours of test, from operating at the ultra-high injection pressure levels, well beyond normal ratings, due to:

a. Lack of strength of the steels used

b. Imperfections in the components due to manufacturing flaws (surface and geometry imperfections) or deviations from target dimensions.

2. Two issues need addressing to enable the system and reap the improvements:

a. Ability to increase the toughness of the steel for withstanding the ultra high pressure pulsing.

b. Ability to generate, at near perfect form, the required, well blended geometries that see the ultra-high pulsing pressure fuel.

3. Two methods that are going to be researched and developed to increase the strength of the injector nozzle tip to handle the Ultra High Injection Pressures.

a. For imparting compressive residual stress (CRS), a production compressive residual stress (CRS) generating process will be developed for the interior of the injector nozzle tip region, and particularly for the sac region to result in above a Fuel Systems Engineering target compressive residual stress (CRS) in the sac and in all other key injector nozzle tip surfaces, by developing:

i. A method to seal tip spray orifices without needing precision ground outer tip surfaces.

ii. Load the nozzle with sealed spray orifices on the CRS generating system interconnection.

iii. Load the hydraulic fluid into the nozzle while keeping the spray orifice seals in place.

iv. Integrate all these technologies into a prototype production device.

b. A production precision profiling process for the sac interior and seat area of the tip will be developed to have:

i. Form and geometry conformance to well under 10 microns peak- to-valley

ii. No surface flaws that come anywhere near 2 microns peak-to-valley.

\section{RESULTS AND DISCUSSION}

\section{7a. Compressive Residual Stress Insertion (CRS) process development for injector tips-}

$3^{\text {rd }}$ Quarter 2010 Accomplishments: In the first quarter of work, the third quarter of 2010, a low cost, simple sealing system was developed and demonstrated to be able to perform CRS generation in any number of standard tips in succession without fail. Computed Tomography (CT) X-ray was carried out on every tip before they were had CRS insertion, to be repeated afterward to measure the surface movement associated with the insertion of the CRS. Discussions were carried out with the CRS process supplier to plan a sequence of tests for developing a process development plan. Special tooling was developed to expedite the CRS processing of high numbers of tips and then to carry them to fatigue test without any 
disassembly. More than 20 tips can be built-up, loaded CRS processed and fatigue tested without any intermediate disassembly and reassembly. This results in the ability to demonstrate production levels of very low failure of the process, and makes the first step toward ability to CRS process tips at production cycle rates. Initial discussions were conducted with the CRS process provider and our targeted system integrator for the production CRS process, to provided a first design proposal of an automatic, robotic-assisted machine, to run at target cycle times and cost per tip.

$3^{\text {rd }}$ Quarter 2010 Activities: 1. The UHIP team did verify that the production sealing methodology for sealing the spray holes of the injector tips will work for multiple tips in a row, and that the method is robust even if a portion of the sealant becomes misplaced. Upon relocation of the sealant, the reworked seal works in the CRS generation process cycle, convincing the UHIP team that we can expect to be able to CRS generation process 10, 20 or 30 tips at a time without any failures.

2. With this success the UHIP team has designed and ordered tooling to assemble 20 tips at one time with the sealant, with the improvement that the containment of the sealant will remain in place after one assembly tip in the tooling, even when transferring the tip in the tooling from the seal test, to the CRS generation process and finally to the pulse fatigue test. At the end of this reporting cycle the components for the 20 tooling sets are in the final stages of being completed. The expectation is that the UHIP team will have the complete set returned in November and the full test of 20 to 30 tips completed in the $2^{\text {nd }}$ quarter.

3. Previous tests with the precision expensive sealant indicated that a single tip must be cycled through the CRS generation process three times to be able to pass the pulse fatigue test consistently. So the UHIP team developed a test plan for combining the few pieces that already have successfully generated CRS inserted with the first batch of 20 that will have CRS generation with the new tooling to test this requirement. The UHIP team hopes to show that one or two CRS generation cycles is sufficient and so reduce the process cost.

4. Multiple discussions were conducted with the CRS generation process supplier and their US arm about how to automate the CRS generation process toward a production process and machine. A representative of the CRS generation process supplier the parent company in Europe, was on a US visit, and meetings were conducted to relay our needs of the production process and consider ideas from both sides on what would be required for a reliable, high volume, low cost production process.

5. CT X-ray was carried out on the multiple tips that were successfully CRS insertion processed in sequence, without failures, both before and after the successful one CRS generation cycle. These before and after CT X-rays are were later analyzed to detect surface movement from the insertion of compressive residual stress.

$3^{\text {rd }}$ Quarter 2010 Risks, Issues, Concerns: The UHIP team needs to find a way to be able to perform the CRS process for a few dollars per tip. The CRS Generation process supplier charges $\$ 200$ per cycle of their machine or \$200 per tip to perform the CRS Generation process as a service. The UHIP team needs to study the process to determine the actual cost per cycle for an in-house process, and then determine how many tips are needed to have CRS inserted per cycle to reduce the cost per tip to the needed level. Then this volume of tips in one cycle, including the cycle time to load the machine and perform the process, needs to be compared to the projected production volumes of these new tips that will incorporate this process.

$4^{\text {th }}$ Quarter 2010 Accomplishments: Five tips were successfully CRS processed with the targeted CRS generation pressure, without fail using the low cost sealing system and they were then abuse tested with $15 \mathrm{megaPascal}(15 \mathrm{MPa})$ to target abuse pressure cycling at $15 \mathrm{Hertz}$ cycling with the same low cost sealing system. They all reached the target cycle count in this 
abuse test. Twenty two (22) fixtures to hold tips with the low cost sealant system are were produced, and put into use. These sets of tooling enabled tips, after applying the low cost sealing system, to go from 10MPa low pressure seal test to the CRS process, and then directly to the cycling abuse test without ever releasing the sealing pressure from the sealing systems. Twenty two tips were CRS processed using these 22 fixtures and 14 were target abuse cycle tested successfully to the full cycle target.

$4^{\text {th }}$ Quarter 2010 Activities: 1 . The UHIP team did show that the standard CRS generation process controls of reaching the target static hydraulic pressure above $93 \%$ of the target CRS generation pressure with only low level leaks verifies a successful CRS generation cycle and insertion of desired compressive residual stress.

2. The UHIP team did develop the ability for above 20 tips at once to assemble the tips with their low-cost sealant system and keep this assembly intact through $1 \mathrm{MPa}$ seal test, CRS generation process at the target CRS generation pressure and the target abusive max pressure pulse cycle test, which will greatly accelerate testing and process development to full robustness and capability.

3. When the UHIP team started developing this production CRS generation approach, the opinion of our material scientists from their previous work, was that the CRS generation cycle needed to be repeated three times on the same tip to reach the CRS level needed. The CRS generation process supplier people said it should not matter, that only one cycle gives the full result. The UHIP team's tests in this quarter showed that tips with a single CRS generation cycle or tips with two cycles all passed the target abuse pressure cycle test just as did the tips with three cycles. So the UHIP team determined that two cycles are sufficient and intended then to test further to determine if one cycle is sufficient.

4. In this quarter, the UHIP team target abuse pressure cycle tested five tips that were successfully CRS generation processed in the first quarter, with the new fixture design. One tip failed to pass due to a problem in the sac area (crack or failure to seal), three tips failed to pass because the new fixture design caused edge loading at the inlet chamfer to the tip, and one tip fully passed the full target abuse cycle count. This resulted in a redesign of the problem aspect of the fixtures, and performing a 14 fixture test in this quarter. The result was that no tip failed due to this redesigned aspect, and 14 completely passed. The UHIP team was then confident that the design of the 22 fixtures is good.

5. The UHIP team determined that the vacuum loading method of the low cost sealing system is not as reliable on tips with their sac outer surface ground than on tips with the outer surface is left as normally produced. Possibly this is due to the grinding leaving the outer spray hole edge with a sharp non-circular shape, or that a burr is raised.

$4^{\text {th }}$ Quarter 2010 Risks, Issues, Concerns: 1 . The UHIP team still needs to find a way to be able to perform the CRS Generation process for a few dollars per tip, such as with gang tooling to do 16 to 20 tips at once, consider how to load this many tips into the machine and perform the process, and compare this projected approach to the projected production volumes of these new tips that will incorporate this process.

2. The Caterpillar Fuel Systems Operations - Pontiac in Pontiac, Illinois may not be willing to implement this process, since it is a new technology to them, but since this CRS Generation process can be done on an otherwise fully finished part, it could be done outside of Caterpillar Fuel Systems Operations - Pontiac in another Caterpillar location.

3. Vacuum loading of the low cost sealant seems to be bothered by the outside of the tip being ground. The root cause for this is not yet understood. The low cost sealant can still be applied manually to these outer diameter (OD) ground tips, using grease to hold the sealant on the tip. Possibly the grease just happens to overcome the sealing reduction of this condition, because under the target CRS generating pressure, the grease becomes a solid. Fortunately, for the 
non-ground, as-machined tips from Caterpillar Fuel Systems Operations - Pontiac the vacuum loading still tends to work quite well.

4. The target CR600 tip (one fuel system version of the UHPCR technology) that will receive the CRS Generation process is being changed still in its design. So for the CRS Generation process the UHIP team will stick with the CR600 design that was used to make the 22 sets of tooling to develop the process. 250 of such prior design tips will be able to be attained, and after reviewing the remaining work for this project, it was decided that the 250 pieces should be sufficient to finish developing the CRS Generation process for the purposes of this project.

$1^{\text {st }}$ Quarter 2011 Accomplishments: The CRS generation process was successfully carried out on 43 tips to the target CRS generating process value, without fail, using the low cost sealing system, that was applied to the tips using the projected high volume application process. They were then abuse tested, cycling between $15 \mathrm{MPa}$ to the target peak cycle value at $15 \mathrm{Hertz}$ cycling with the same low cost sealing system. They all reached the target number of cycles in this abuse test, with no failures assignable to tip failures from fatigue. These tips all were done with standard tip geometry, with no precision outer surface machining to suit the sealing system. The low precision lowest cost sealing system was successfully used to carry out the CRS generation, and then to carry out the fatigue testing on these standard production geometry tips. Discussions were conducted with the high pressure equipment supplier toward the possible mechanisms and structure of a production system CRS generation machine that could operate at production line rates. A first proposed approach was achieved and agreed upon.

Figure 1 below shows the CT X-ray measurement depicting surface movement in the compression direction for all but 5 tips. The fact that the 5 showed surface movement in the tensile stress direction we believed was the result of drift of the CT X-ray that would have to be better controlled to be removed in the next round of testing.

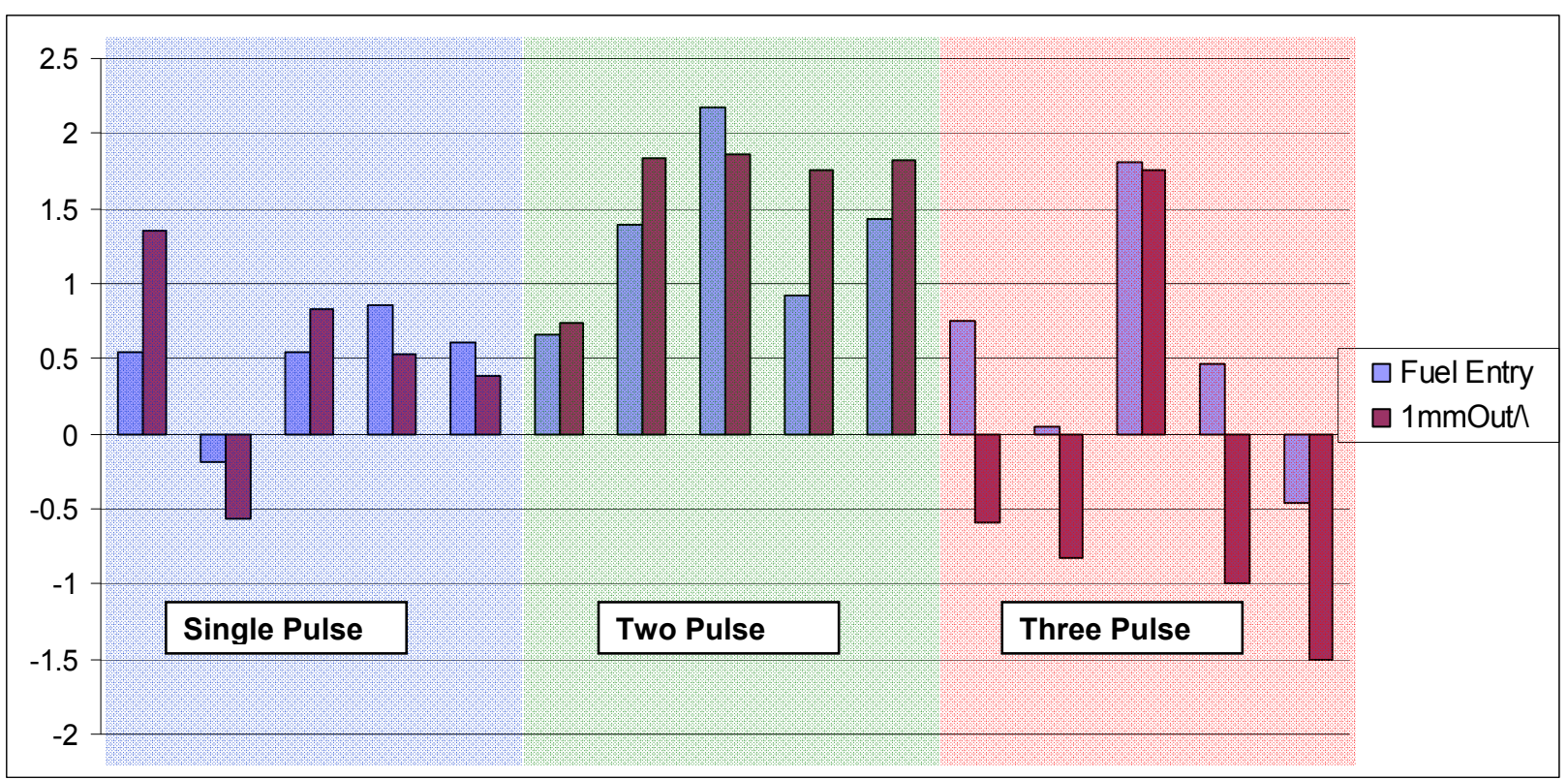

Figure 1. First 15 tips with CRS generation: five with one pulse, five with two and five with three. The vertical axis is in normalized surface movement units. Note that some show surface movement apparently in the wrong (tensile) direction. 
$1^{\text {st }}$ Quarter 2011 Activities: 1. The UHIP team showed in this quarter that the CRS generating process using the lower precision lowest cost sealant on standard production low precision geometry tips, was $100 \%$ successful in generating tips that pass the abuse test that Caterpillar Fuel Systems - Product Development uses to determine the successful accomplishment of reaching required tip durability for approaching 50 tips to that point. In the latest run of 24 tips, this was fully accomplished using the projected high volume production method of applying the low cost sealant. This showed strongly that this process is quite robust and can be carried out with successful capability in high volume production.

2. The UHIP team showed that sufficient CRS insertion was being reached to pass the Caterpillar Fuel Systems - Product Development fatigue test with only a single cycling of the CRS generation process.

3. CT X-ray was verified capable to measure the degree of CRS application to injector tips.

4. The UHIP team moved ahead with planning the mechanisms and structure of a production machine that will be able to carry out this process in a production setting at line rates.

5. The UHIP team is moving significantly closer to having a production process that could cost only a few dollars per tip if not approaching one dollar per tip.

$1^{\text {st }}$ Quarter 2011 Risks, Issues, Concerns: 1 . The UHIP team still requires that the chamfer at the other end of the tip opposite the sac region be ground to avoid cracks from stress risers or leaks in the CRS generation process. The UHIP team would like to find a way to avoid this grinding process and simply be able to operate with the normally produced chamfer quality.

2. The UHIP team now needs to confirm that the process is not causing any change to the outer profile of the injector tip around the spray holes.

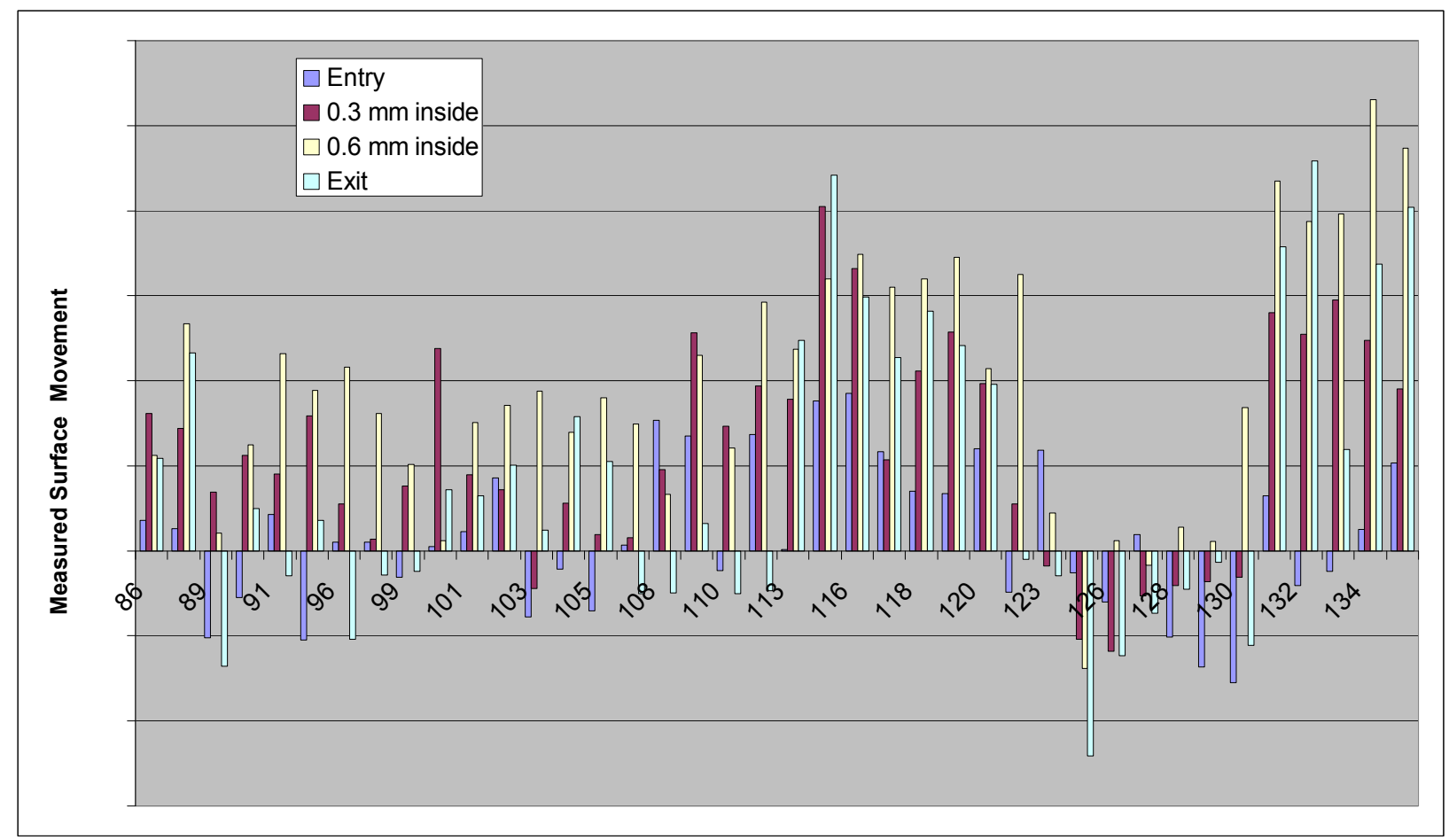

Figure 2. Measured surface movement in 43 tips. Target movement is to be greater than the first grid line above the horizontal axis. Note some tips measured to have reverse movement.

3. The target CR600 tip that will receive the CRS generating process is being changed still in its design. It was decided that the ongoing CRS generating process development will continue to 
use the CR600 design for which there are the 25 sets of tooling in hand. The UHIP team is obtaining around 50 of such prior design tips to continue the next process development tests. The UHIP team has determined some minor changes to the tooling componentry that will accept the new design of tips and these alterations could be carried out when necessary to continue the work, especially into the automated production process machine development phase.

4. The 43 tips completed fatigue tested without any tips failing, but as seen in Figure 2, several tips numbered between 124 to 130 showed the surface movement in the CT X-ray reversed direction to depict that these surfaces were showing to have gone into the tensile stress region. This cannot actually be true because they all passed the abuse test, so it must be a problem with drift in the CT X-ray measurement. This must be resolved in the next round of testing.

$2^{\text {nd }}$ Quarter 2011 Accomplishments: CRS generation on another 40 tips was 100\% successfully completed to the target CRS generating process value, without fail, using the low cost sealing system that was applied using the projected high volume application process. These 40 were CT X-ray measured both before and after the CRS generation process, measuring each twice before and after so that a measurement capability study can be completed on the CT X-ray measurement method. Another method of measuring the degree of CRS was identified that is a more traditional method of tip performance measurement used in tip production. This method was also carried out before and after the CRS generation process was done. These 40 tips all were done with standard tip geometry, with no precision outer surface machining to suit the sealing system. The low precision lowest cost sealing system was then successfully used to carry out the CRS generation, and was to also be used in the $3^{\text {rd }}$ quarter time frame to carry out the fatigue testing on these standard production geometry tips. A visit to headquarters of the high pressure equipment supplier was completed so that the UHIP team could see the breadth of their production facilities. They showed us that they had tested a sequence of automatically applying the sealant system, with success, so they were at that point confident they could automate a full process this way. We then discussed further the possible mechanisms and structure of a production system CRS generation machine that could operate at line rates. Further refinements over the first proposed approach were discussed and agreed upon. A TRL Review was conducted and this CRS generation process was at that time approved to TRL3.

$2^{\text {nd }}$ Quarter 2011 Activities: 1.40 more tips were pre-measured and had successfully applied the CRS generation process without a single miss, using the projected high volume production method of applying the low cost sealant. The pre-measurement included carrying out CT X-ray measurement twice in randomized order with as careful calibration as could be done, to be able to evaluate the total measurement uncertainty of the measurement process. The UHIP team also used a traditional production measurement method used for evaluating tips, because it is believed it might be able to measure the degree of CRS insertion. With the CRS inserted in these tips, post process measurement was carried out using both CT X-ray and the traditional production method. A Measurement Systems Analysis (MSA) was planned to be carried out on CT X-ray measurement

2. Once the post measurement was done, the UHIP team scheduled to perform the Caterpillar Fuel Systems - Product Development fatigue test at Caterpillar Fuel Systems Operations Pontiac. Expectation was to have a complete success in this test as was experienced in the past, and then have nearly 100 tips having passed. This then would show that the CRS generation process, using the high volume production steps, is a fully capable process.

3. The UHIP team was confident at that point of CT X-ray's ability to non-destructively measure the degree of CRS application to injector tips, and was studying how to reduce its uncertainty. 
4. In our visit to the CRS generation process supplier in June, they showed that they have a clear understanding of the sequence for applying the low cost sealant system in an automated way, how to apply the sealing method they plan to use, then how to complete the CRS generation, remove the part and clean the sealant off reliably. The UHIP team asked them then to deliver a machine specification and budgetary quote.

5. The UHIP team continued to move significantly closer to having a production process that could cost only a few dollars per tip if not approaching one dollar per tip.

$2^{\text {nd }}$ Quarter 2011 Risks, Issues, Concerns: 1. The UHIP team still requires that the chamfer at the other end of the tip opposite the sac region still requires being ground to avoid cracks from stress risers or leaks in the CRS generation process. The UHIP team would like to find a way to avoid grinding and simply be able to operate with normally produced chamfer quality.

2. The UHIP team will continue to check that the sealing process is not causing any change to the outer profile of the injector tip around the spray holes.

3. The target CR600 tip receiving CRS generation continues to be under design change. So for the CRS generating process the UHIP team did obtain and are completing the processing of 50 of the prior phase tips that our 25 sets of tooling are designed for to develop the process.

4. For further work, minor design changes to the tooling componentry have been identified that will accept the new design of tips and these alterations can be made to continue the work, especially for any work for developing the automated production process machine.

$3^{\text {rd }}$ Quarter 2011 Accomplishments: No further CRS generation on tips was done, but work continued on the 40 tips that had CRS generation completed in the $2^{\text {nd }}$ quarter of 2011 . Two rounds of fatigue testing were completed in this quarter. Only 24 tips were able to be tested in the two rounds due to our UHIP high number of tests at their full peak pressure cycling causing hardware failures on the pulse fatigue rig. These hardware failures reduced the maximum number of tips that could be tested in a single pulse fatigue test to be down from 18 to 12 . The first batch of 12 was completed in mid-August with 11 new tips all passing the target abuse cycle and one repeat tip for higher cycles passing the target abuse cycle count. The repeat tip then was up to three times the target abuse cycles count. The second batch was completed late in the quarter with12 tips tested, eight new passing the target abuse cycle count, two repeat tips that are now with one at four times the target abuse cycle count and one at three times that count. Two failures at early cycle count ( $2 \mathrm{~K}$ cycles and $160 \mathrm{~K}$ cycles) occurred, which were after final analysis due to relaxation of the spring load over 4 months of waiting for the fatigue testing. Of the 40 tips with CRS insertion we had at that point 18 new tips passed and two tips at very high cycle count still passing. At this point we had 75 tips passing. The remaining $20 \mathrm{CRS}$ generated tips still not fatigue tested were planned to be completed in the next quarter.

One concern was to see if the CRS generation process imparts tensile residual stress to the internal precision ground conical seat of the tip. Below in Figure 3 is the surface movement as measured by the CT X-ray. The portion from $Z$ height $0.0 \mathrm{~mm}$ to $0.9 \mathrm{~mm}$ is the conical blend from the check seat to the sac. The portion from $0.9 \mathrm{~mm}$ to $1.2 \mathrm{~mm}$ is the surface movement of the ground check seat. It appears from this measurement that the CRS generation causes tensile stress in this check seat area. This was tested by placing continuous and increasing load on the seat up to the failure of the tip. Both tips without CRS generation and tips with CRS generation were tested and all tips broke at the same loads within test uncertainty. Caterpillar Fuel Systems - Product Development was then convinced that the CRS generation process does not weaken this internal seat area. 


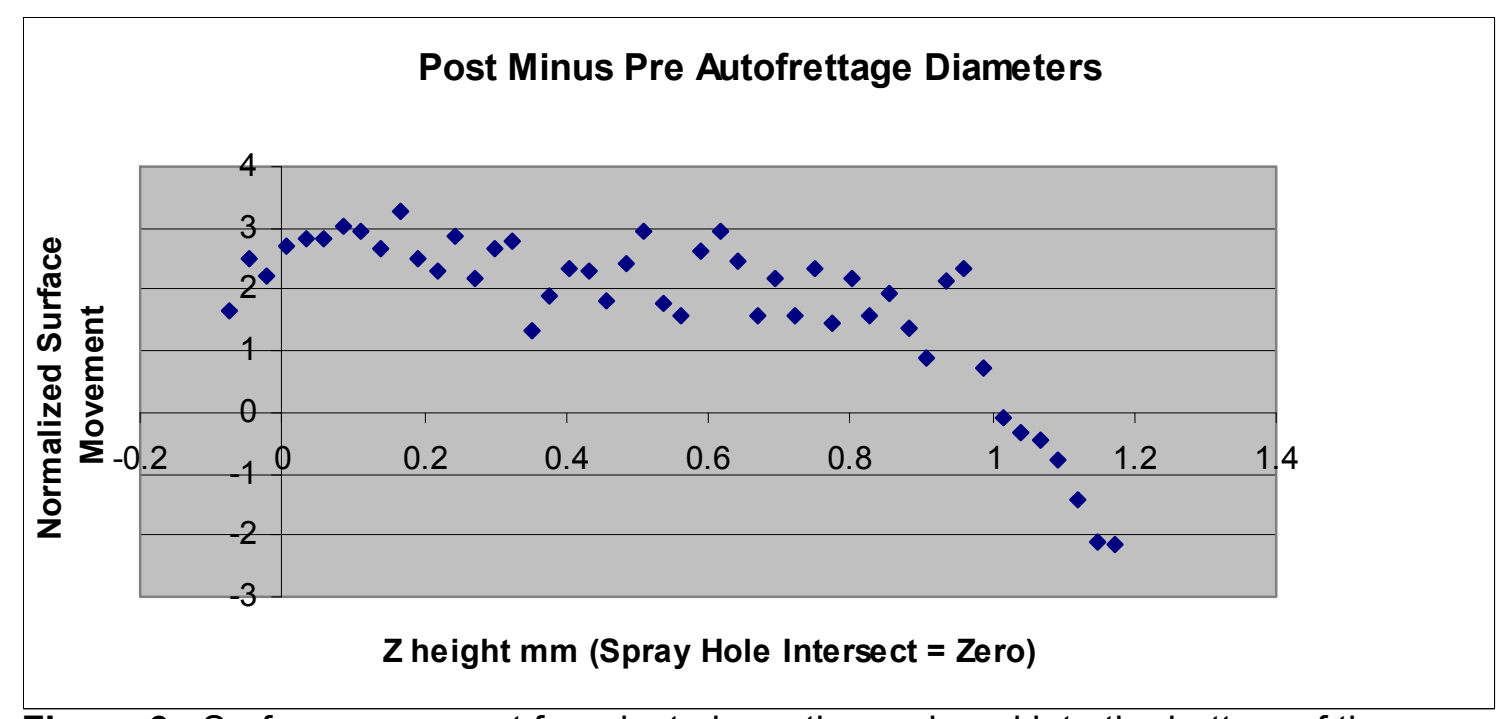

Figure 3. Surface movement from just above the sack and into the bottom of the ground check seat. Note the ground check seat appears to receive tensile stress from the CRS generation process

The UHIP team continued to look for a method to measure CRS insertion in production. Before ad after flow measurement was tried in this quarter, and as seen in Figure 4, it was found that the difference was not significant compared to the noise of the flow measurement process, demonstrating that this idea was, in all probability, not going to be successful. This would make sense, because flow is controlled predominantly by the smallest opening, particularly if the smallest opening is at the outlet, which is the case for these tips.

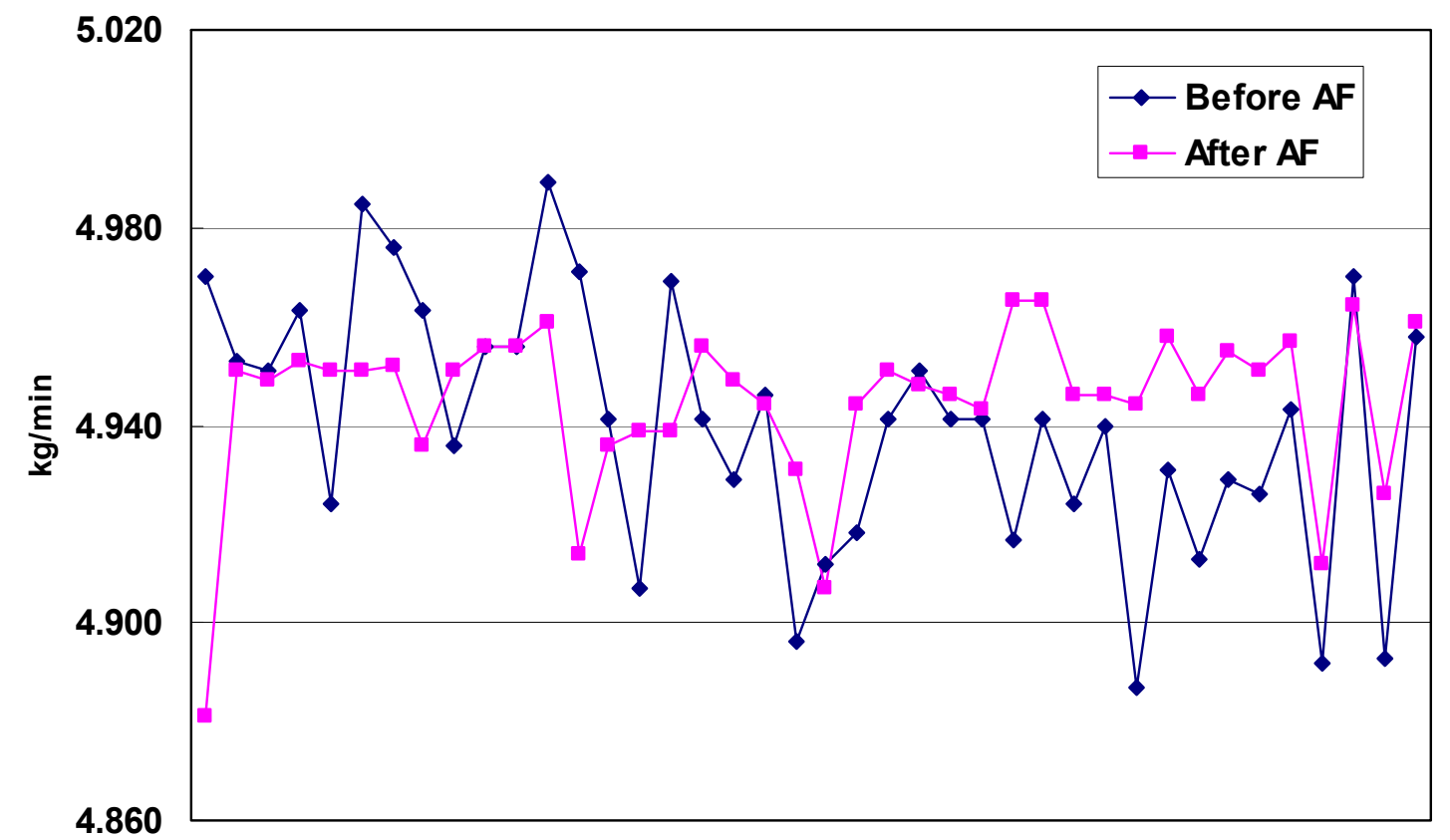

Figure 4. Flow results on 40 tips from before to after the CRS generation. This showed that tip flow does not change significantly from before to after the CRS generation process. 
A presentation of all results to date was given to Caterpillar Fuel Systems - Product Development and Caterpillar Fuel Systems Operations - Manufacturing Engineering/Quality and their management. It was decided at these presentations that the CRS generation process had at that point been successfully demonstrated. These engineering teams at that point began fully anticipating that tips and other injector components would include the production hardened CRS Generation process as part of normal component production processing. The CRS generation process was approved to TRL3 level and it was planned to complete a TRL4 review in this third quarter. At this point, the UHIP team discovered that the CT X-ray digital panel was decayed to the point that the after-CRS-generation measurements were unacceptable (within the necessary minimal micron level of uncertainty). As a result the after CRS generation tip measurements were unable to be completed. The UHIP team asked the Caterpillar Fuel Systems Operations - Manufacturing Engineering/Quality to redo the after-CRS-generation measurements on their machine in Pontiac, Illinois, following our careful calibration of their machine the same as was completed on the Tech Center machine. If this is successful, the TRL4 Review could then be completed.

$3^{\text {rd }}$ Quarter 2011 Activities: 1. No more tips had CRS insertion done on them as the UHIP team are continued to work on the 40 that were completed in 2Q2011. Twenty-one tips were successfully fatigue tested at maximum abuse pressure levels, 18 new tips (never before fatigue tested) and three tests of prior tested tips. The UHIP team at this point had 75 tips successfully through the abuse cycle count, one tip through four times the abuse cycle count and one tip through three times the abuse cycle count. Two tips had early cycle count failure $(2 \mathrm{~K}$ and $160 \mathrm{~K}$ cycles) which is suspected to be due to relaxation or settling of the spring load on the low cost sealant system in the four months of waiting for the fatigue test.

2. The 40 tips with CRS generation were re-CT X-rayed, half that have not seen fatigue testing, and half that have.

3. The UHIP team eliminated the possibility that the internal conical seat is weakened by the CRS generation process for the sac region. A press load test showed that tips with CRS generation failed the same within test uncertainty as did those without. Caterpillar Fuel Systems - Product Development was satisfied that the CRS generation process only strengthens tips.

4. A presentation to the end customers of the CRS generation process was given, with full acceptance and with Caterpillar Fuel Systems Operations - Manufacturing Engineering/Quality now requesting that any acquired machine for the production hardening process be placed in Caterpillar Fuel Systems Operations - Pontiac for full process development.

5. The UHIP team was at TRL3 status then, planning to complete TRL4 status in 4Q2011.

$3^{\text {rd }}$ Quarter 2011 Risks, Issues, Concerns: 1 . The UHIP team still requires that the chamfer at the tip end opposite the sac region still requires being ground to avoid cracks from stress risers or leaks in the CRS generation process. It would be advantageous to find a way to avoid this grinding process and simply be able to operate with the normally produced chamfer quality.

2. In the latest round of fatigue testing, two tips experienced low cycle failure ( $2 \mathrm{~K}$ and $160 \mathrm{~K}$ cycles) and the UHIP team has yet to determine the root cause, although it is suspected that the root cause is the relaxation of the spring load on the low cost sealant system in the four months of waiting for the fatigue test. The UHIP team need to pay close attention to this until a root cause is determined, hoping to learn how this effect could be handled in such a way as to not be a problem in production.

3. The UHIP team continues to look for a method to measure the level of CRS imparted in a production process. Before and after flow measurement was tried in 3Q2011, and found that the difference was not significantly outside the noise of the flow measurement process.

4. For CT X-ray of CRS generation, using before and after CRS generation CT X-ray measurements, the results were not good. Further analysis showed the Manufacturing 
Technology Division CT X-ray digital panel was decayed to the point that it could no longer make good measurements (within the necessary minimal micron uncertainty band). All final analysis work was delayed by this unexpected development. The UHIP team then began a process to acquire another digital panel for the machine. Since the cost is around $\$ 80 \mathrm{~K}$, it could not happen quickly, as we had to find an unplanned budget area in the Caterpillar Product Development and Global Technologies Division with which to fund it. In the mean time, the UHIP team gained approval to have the Caterpillar Fuel Systems Operations - Manufacturing Engineering/Quality in Pontiac redo the after CRS generation measurements using their newer CT X-ray, following our careful calibration and accuracy checking process. Results were expected to be completed in 4Q2011. For precision sac profiling it was decided that even with the degraded digital panel, that the CT X-ray measurements could be used. Analysis even on the Precision Profiling process were also delayed due to the lost time in determining how to proceed.

$4^{\text {th }}$ Quarter 2011 Accomplishments: No further CRS generation on tips was been done. In the $4^{\text {th }}$ quarter 2011, the UHIP team completed fatigue testing the 40 tips that had CRS generation already completed in the $2^{\text {nd }}$ quarter of 2011 . Two more rounds of fatigue testing was completed to finish all planned fatigue testing of all remaining tips. No tip failures were observed in these two rounds. Before these two rounds the UHIP team had 75 tips completed by the end of Sept, 2011. With these two rounds, 95 tips have gone through the full target cycle level at the abuse load pressures with absolutely no tip sac assignable failures. Two high cycle tips were repeatedly tested, reaching five and six times the number of abuse test cycles required, also without failure.

In the $4^{\text {th }}$ quarter 2011, the UHIP team was convinced from our data that the only tensile stress placed on tips via the CRS generation process is in the form of elongation of the tip by about the amount of our target surface movement, and overall increase of the diameter by a similar amount, both of which were never observed to degrade the tip strength in any measureable way. Caterpillar Fuel Systems - Product Development remained convinced from our testing that the CRS generation process does not weaken the tip significantly in any way.

Since no method was found to measure CRS insertion process in production, the UHIP team settled with the plan to monitor only CRS generation process parameters to insure that CRS is generated in the work piece. If there is doubt whether a tip has been run or not, or has sufficient CRS out of a cycle, it will simply be run again, as the UHIP team had learned that multiple CRS generation cycles does not degrade the tip. Multiple presentations of all results to date were given to Caterpillar Fuel Systems - Product Development, Caterpillar Fuel Systems Operations - Manufacturing Engineering/Quality and their management, all of whom expressed confidence that the UHIP team had been successful in fully demonstrating a reliable and capable CRS generation process.

We did perform a MSA of the CT X-ray measurement of surface movement due to the CRS generation process. We found that from the 40 pieces measured two times before CRS generation and two times afterward, using the standard MSA procedure from the Automotive Industry Action Group (AIAG) that this surface movement process $6 \sigma$ spread consumes about $49.7 \%$ of our expected surface movement band. It was also noted that all the data taken on these pieces (80 measurements) shows that the $6 \sigma \mathrm{Cp}$ of the total process (surface movement plus the measurement error) consumes about $64.65 \%$ of our desired surface movement band. From this, the estimated $6 \sigma$ process width without the measurement width consumes about $41.4 \%$ of the desired band of surface movement, using standard root mean square arithmetic. Then using the total process $6 \sigma$ width (from both surface movement width plus measurement 
width) in a Cpk calculation, we see that the process has a Cpk of 1.23, which is an acceptable value. So we can say that we can monitor the CRS generation process parameters, and monitor the total process Cpk, and if the process parameters stay above targets and within windows, and this Cpk stays appreciably above one then we can be confident of our quality.

These engineering teams at that point had incorporated plans and budgets for further development toward full production hardening for tips and other injector components that need strengthening for UHIP in 2012. The CRS generation process is now approved to the TRL4 level. The UHIP team was able to complete the TRL4 review, by using data from the CT X-ray at our Pontiac plant. It also was determined in carrying out this post-process measurement on a different machine, that with the careful calibration and calibration checking procedures developed in this project, the results can still show both a very high level of correlation and a necessary minimized band of uncertainty.

$4^{\text {th }}$ Quarter 2011 Activities: 1. Analysis and fatigue testing were completed on 40 more tips with careful calibration, correlation to a known master, and multiple recalibrations during CT Xray run intervals. The UHIP team reached 95 tips through fatigue testing, with no failures attributable to the strengthened sac, lower tip regions or spray holes. We had two tips at five to six times the full single fatigue testing target number of cycles without failure.

2. CT X-ray measurements were completed twice before CRS generation and twice after with careful calibration and correlation. This time the measurements consistently showed the surfaces move in the proper direction for CRS generation with no anomalies (see Figure 5) proving that previous reversals were due to less careful calibration and measurement methods.

3. The capability of the measurement process was shown to be down to the needed micron level of uncertainty. Caterpillar Fuel Systems - Product Development and Caterpillar Fuel Systems Operations - Manufacturing Engineering/Quality are very satisfied that the CT X-ray measurement of surface movement in the surface compression direction is solid evidence of successful CRS generation. Caterpillar Fuel Systems - Product Development is now completely satisfied that the CRS generation process only strengthens tips.

4. A presentation of the CRS generation process results was given to end customers, resulting in full acceptance. Caterpillar Fuel Systems Operations - Manufacturing Engineering/Quality now demands that any acquired machine for the production hardening process be placed in Caterpillar Fuel Systems Operations - Pontiac facility for final process development.

5. We attained TRL4 status for the CRS generation process. 


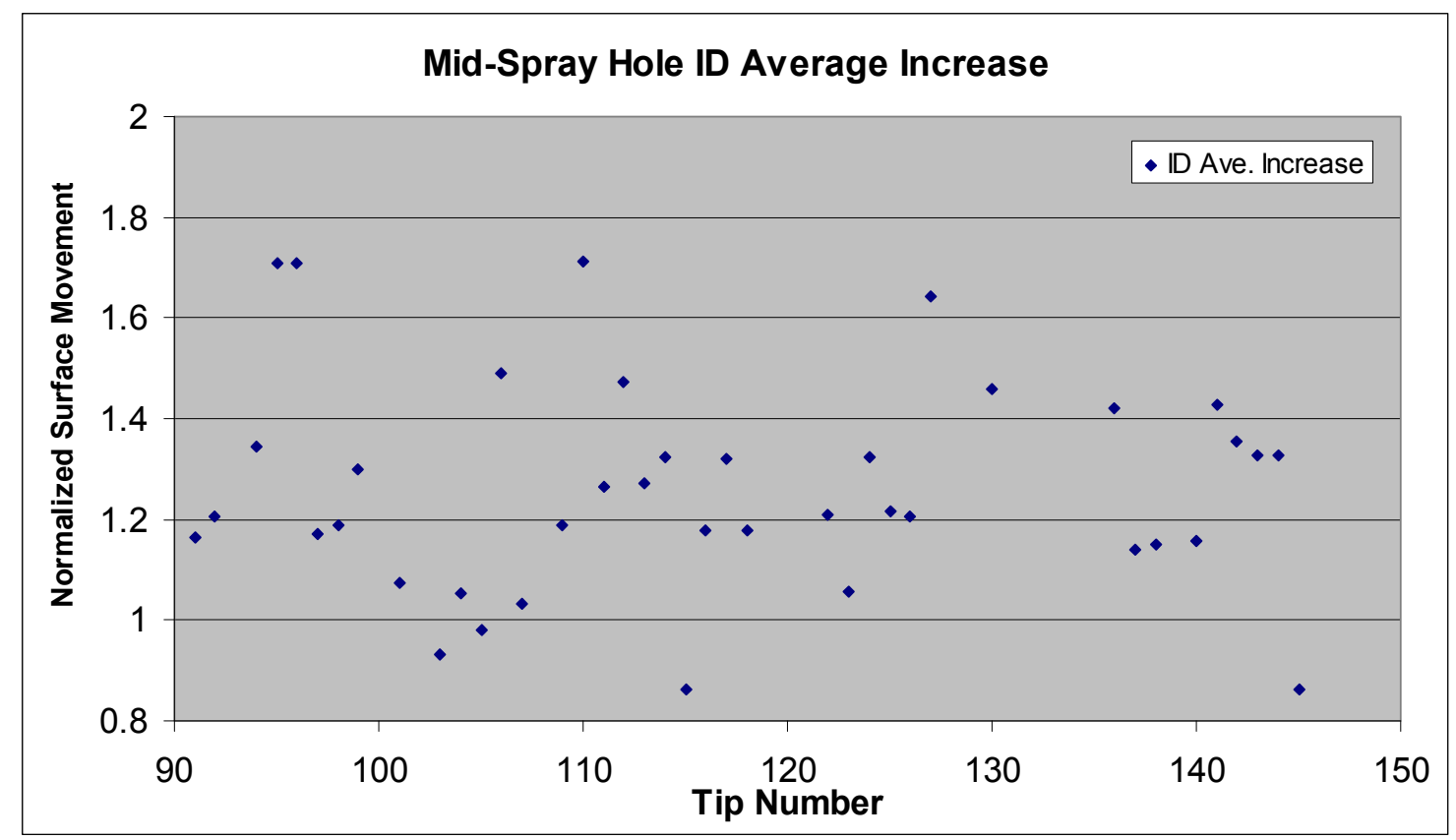

Figure 5. The final 40 tips to have CRS generation, result of before and after CT X-ray. Note that none of these tips showed the reverse direction of surface movement, proving that careful calibration and metrology methodology was effective to eliminate errors.

$4^{\text {th }}$ Quarter 2011 Risks, Issues, Concerns: 1 . The chamfer at the other end of the tip opposite the sac region still requires being ground to avoid cracks from stress risers or leaks during the CRS generation. The UHIP team would like to find a way to avoid this grinding step and be able to operate with the normally produced chamfer quality.

2. For process control, the UHIP team has decided to monitor the process parametrics from the CRS generation machine, recording data to show the CRS generating pressure reached the required threshold with no leaks, insuring successful impartation of CRS. Based on our results, Caterpillar Fuel Systems Operations - Manufacturing Engineering/Quality accepts this approach. If a set of production tips occurs where Caterpillar Fuel Systems Operations Manufacturing Engineering/Quality is uncertain whether they were cycled to receive the CRS or not, they can be reprocessed with no detrimental effect, because we have shown that tips processed multiple times still show no detriment, still passing fatigue testing without fail. Caterpillar Fuel Systems Operations - Manufacturing Engineering/Quality has also accepted this approach for this condition.

\section{Completion of Statement of Project Objective (SOPO) Tasks and Subtasks for the CRS Generation Process}

Task 2.0 Development of Individual Techniques for Production CRS Generation is $100 \%$ complete as shown in the following breakdown:

Subtask 2.1 Testing methods to seal orifices is $100 \%$ complete.

Subtask 2.2 Testing production rate application of orifice sealant to tips is $100 \%$ complete in that our optimum desired approach is working without fail.

Subtask 2.2a The preferred Subtask is $100 \%$ complete.

Subtask 2.2b The preferred method of applying the sealant rarely left excess sealant on the tip, but if excess did remain, removal was trivial without disturbing the properly located sealant. The machine supplier has demonstrated a reliable method, so this Subtask is $100 \%$ complete. 
Subtask 2.2c The preferred design and method of applying the outside containment tooling to hold the sealant in place for the ultra-high pressure CRS generating process is working without error, so this Subtask is $100 \%$ complete.

Subtask 2.2d The preferred method used of filling the tip with the high pressure fluid and eliminating voids worked successfully without problem, so this Subtask is $100 \%$ complete.

Subtask 2.2e We learned that reaching a certain level of CRS generating pressure, greater than $93 \%$ of the ultimate target value with minimal leaks, insures a passing tip in the target cycle fatigue test. So only noting the final obtained CRS generating process pressure and the level of leak present are required to ensure a strong tip. The supplier has incorporated these measures into the process self-monitoring, as data to be read-out and recorded. Therefore, the actual application of the CRS generating process pressure and testing for sealing integrity are at a $100 \%$ level of completion.

Subtask 2.3 We now have completed testing the reliability of achieving good CRS generation with the low precision, low cost sealant, using the production sealant loading method applied for 100 tips. The CRS generation process has been completed on all tips, and all post measurements are now finalized as well, including the CT X-ray improved methodology. The analysis is finished and the fatigue tests have been run on 95 tips with no failures. Therefore, testing the sealant for its robustness for successful CRS generation is now $100 \%$ complete.

Subtask 2.4 We have completed this task using the CT X-ray measurement, attaining TRL3 status. Our 95 tips have passed the full fatigue testing without a single failure, while tips without CRS processing fail this test at about a $50 \%$ level. Thus, we are certain that the required level of CRS is applied and the CT X-ray measured surface movement is real, with sufficient evidence of reliable CRS presence without need of further confirmation. Caterpillar Fuel Systems - Product Development and Caterpillar Fuel Systems Operations - Manufacturing Engineering/Quality are convinced of the reliability of CT X-ray, so this Subtask is complete.

Subtask 2.5 Our target CRS generating process supplier, with their automation equipment on our sample parts and tooling, continues to see improved reliability of their automated process to reach consistent attainment of CRS. They have visited our facilities in Nov, 2011 to discuss further progress, providing us progress on their quotation for the machine we need with the level of automation, and progress on their tests toward full automation reliability. Therefore, development and testing of automation methods is $100 \%$ complete.

Task 3 CRS generating process production hardening is $100 \%$ complete, as we now know that the low precision sealant works well on low precision (unground) sac exteriors, requiring only one CRS generating cycle per tip. We also have our target CRS generating process supplier making further progress on their automated process based on this method. They have bench tested our method and proven to themselves that it is viable. They visited in early Nov.2011 and have provided full automated machine preliminary specification, a refined budgetary quote, and a report of the satisfactory results of their testing of their automation methods.

Task 4 Production CT X-ray refinement for CRS generating control is $100 \%$ complete with the attainment of TRL3 status. We now know there is a finite life to the digital panel. A more durable digital panel was acquired from the CT X-ray supplier along with an upgraded tip measurement cycle. A cycle improvement of a factor of two in tip measurement was attained, with opportunity to decrease this time further. We have completed the uncertainty analysis for the CT X-ray and have developed an in-process control plan that is acceptable to Caterpillar Fuel Systems Operations - Manufacturing Engineering/Quality. 


\section{7b. Production Precision Profiling Process for injector seat and sac regions -}

$3^{\text {rd }}$ Quarter 2010 Accomplishments: The UHIP team worked with Caterpillar Fuels Systems Product Development, and determined on a series of three current high volume production injector tip models was chosen as mules for developing the Precision Profiling process that were representative of the UHIP injector tip design and performance. A large sample of fully finished tips of each of the three models was selected, each having a good sampling of the typical kinds of flaws seen from the current sac machining process. One model was one of small size for lower fuel delivery, one of midsize for intermediate fuel delivery, and one of larger size for larger fuel delivery, so we will refer to them from here on in this report as "small size", "midsize", and "large size". The flaws were detected and recorded using digital imaging boroscopy. A cross-section samplings of all of these tips were then CT X-rayed to precision measure their geometry and flaws before the Precision Profiling process. A process development plan was preliminarily discussed and developed with the target Precision Profiling process supplier via meetings at the International Machine Tool Show (IMTS) in Chicago, Illinois and in video conferencing to their headquarters overseas.

$3^{\text {rd }}$ Quarter 2010 Activities: 1. The UHIP team realized that significant volumes of sac flaw and geometry problems need to be found to develop this process and that such volumes would not be able to be found by searching through the small sample sets of the new prototype tips being produced in our normal test cycle. Caterpillar Fuel Systems - Product Development leaders were asked to select some high volume production tip part numbers that could be searched through to develop our sample sets. They did select three part numbers. The UHIP team also realized that large samples of these three part numbers need to be inspected to select flaws and geometry problems for the study. 100\% CT X-ray measurements was not feasible, so the UHIP team used boroscopic microscopy to look at sacs by eye for various inspection needs, but images needed to be captured for further review. The UHIP team found that camera systems were available for very reasonable price for our micro-boroscope, which would store the images as computer files. Such a computer imaging system was purchased.

2. The UHIP team made sample sets of tips with flaws, stored computer images by tip number, and then made CT X-ray images and analysis to measure the deviations of these tips in flaws and geometry before the Precision Profile process.

3. The Precision Profiling process supplier did have a pair of engineers present that the International Machine Tool Show (IMTS) in Chicago in September, and UHIP team representatives spent most of a day there discussing our needs and how to carry out the necessary tests. As a result the UHIP team now has a preliminary process development understanding and plan in place with them.

4. Portions of the sample sets were shipped to the Precision Profiling process supplier. They reviewed our stated requests and the partial sample sets and provided us their first quote for one part number. An order was submitted to them to perform the Precision Profiling process so that they will be able to complete the process in December, 2010.

$3^{\text {rd }}$ Quarter 2010 Risks, Issues, Concerns: 1. Again this process needs to be evaluated for cost per tip, and a plan needs to be developed for how it can be carried out for reasonable cost. The UHIP team expected, as was expected for the CRS Generation process, that this can be carried out with one Precision Profiling process control and generator system to be ganged over several tips at one time. These discussions need to be conducted.

2. The Precision Profiling process will remove stock from the interior of the tip, expected to be on the order of moving the sac surface by some minor fraction of the sac interior target dimensions. This issue may require study to determine if this would require the form drilling to target dimensions to be changed to leave stock for the Precision Profiling process to remove or 
not. Also, the where the Precision Profiling process would fit in the operation sequence needs consideration so that its material removal would complement and not cause degradation to the surface modification of the other operations in the sequence. This discussion needs to occur with Caterpillar Fuel Systems - Product Development and eventually with the Precision Profiling process supplier.

$4^{\text {th }}$ Quarter 2010 Accomplishments: the target Precision Profiling process supplier was shipped the 50 selected samples tips of the three tip models and they notified us that they had received them. The Precision Profiling process supplier then fully Precision Profiled two models, 100 pieces total. The Precision Profiling Process supplier also developed a method to mold or make impressions of the sac interior using fast setting (under three minutes) silastic rubber compound and then measuring on a Mahr MarVS222 computerized measuring microscope, which is able to discriminate down to 5 microns of profile change from the Precision Profiling process. With this, they can now make impressions of the tip both before and after the Precision Profiling process, overlay the two tip sac profiles and determine the amount of material removed and the profile improvement (see Figure 6). The UHIP Project principle investigator visited the Precision Profiling Process supplier for two days, and found they:

a. Had process development approach for our type of injector tip sac interiors well in progress, b. Needed further information on one tip model and that was provided to them during the visit, c. They had developed, as was asked, a very capable way to measure the sac interior incoming condition and the material change their process accomplishes,

d. Their Precision Profiling machine products are well engineered, suitable for high volume production and capable to reach our goals.

The 100 pieces the UHIP team sent were received back from them, and all had before and after Precision Profiling digital boroscope pictures made of the condition of the sac, and bore and after impression metrology for dimensional change. A sample of these 100 tips (about 14 to 20) were CT X-rayed before they were sent to the Precision Profiling process supplier, and will be CT X-rayed after wards to gain this type of 3D comparison of the work they have done. Further discussion with Caterpillar Fuel Systems Operations - Manufacturing Engineering/Quality provided the feedback that they would rather have this process to occur in the unhardened state, right after the tips are OD turned and bore, sac and seat form drilled. With this feedback, it was decided to acquire 50 samples of each of the three part numbers in the unhardened state without spray holes or any internal grinding, with the intent that these 150 soft tips would be shipped to the Precision Profiling process supplier for continued process development.

$4^{\text {th }}$ Quarter 2010 Activities: 1. The UHIP team pushed the Precision Profiling process supplier to develop their own method to perform metrology on their internal tip processing. They were making silastic impressions but simply providing them to their customer for them to evaluate. At our motivation, they did begin using their Mahr MarVS222 system then to computer fit images of their silastic impressions to measure the profiles they are generating. The UHIP team also pushed them to overlay, before and after the Precision Profiling process, what improvement was accomplished, or what stock is removed and what relative change to the profile resulted.

2. The principle investigator visited the Precision Profiling process supplier, to drive them to show their progress and demonstrate their capabilities. They showed the progress on their metrology and process control, and also had about 50 pieces of one part number of the three test part numbers done. They also showed that for a second part number, they lacked the print of the part, which was supplied to them during the trip. The third part number they could not do because the spray hole pattern is cantered, by design, to the symmetry axis of the tip and the sac, which causes problems for the Precision Profiling process. They also showed us the degree of variability of the location or the tip sac interior coming to them relative to the conical 
seat, and what they would have to do to accommodate this. Finally we discussed what they should do to further configure their prototyping Precision Profiling process machine for their further work in this project, and what the ultimate production Precision Profiling process might look like, with what degree of automation and precision is needed.

3. Afterwards they finished the second test part number for 50 more pieces, sending back to us before and after precision digital boroscope pictures, and before and after silastic impression metrology. In the $3^{\text {rd }}$ quarter the UHIP team carried out the post CT X-ray and prepared a full analytical report of this round of work, which was used to secure TRL2 for precision profiling.

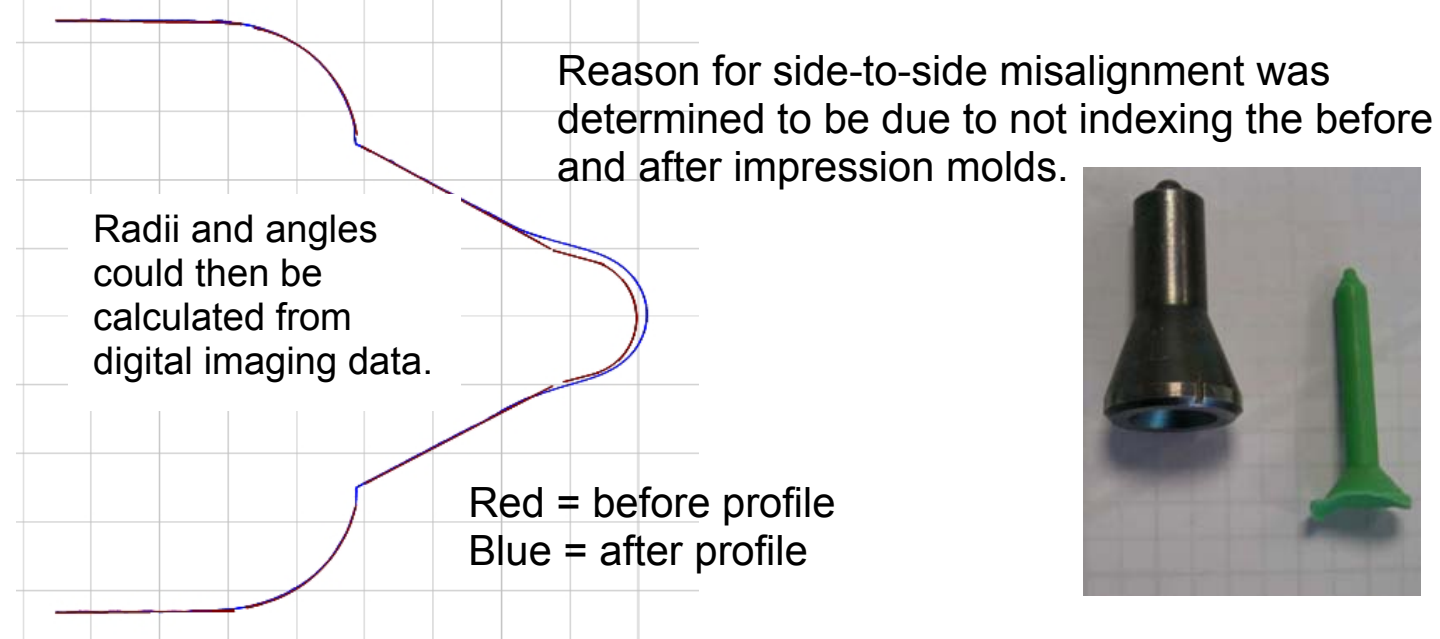

Figure 6. The molding and digital optical comparator capability development by the Precision Profiling process supplier for this project.

$4^{\text {th }}$ Quarter 2010 Risks, Issues, Concerns: 1. The UHIP team learned from the Precision Profiling process supplier that they do not need spray holes in the tip sac to assist their Precision Profiling process, and that they can Precision Profile machine soft tips just as well as they can machine hardened tips. The Caterpillar Fuel Systems Operations - Manufacturing Engineering/Quality wanted to consider this process being done in the soft state. It was agreed that for the next steps stock should be left in the sac for the Precision Profiling process so we procured the three trial part numbers in their soft state with some machining stock and with no spray holes, and we obtained the part prints for such soft state tips.

2. The target CR600 tip that will ultimately be receiving the Precision Profiling process is being changed still in its design. So the Precision Profiling process development continued to use the 3 high volume sample part numbers to develop the process.

3. Ultimately a "tip sac breaker" process will need to be developed that can see how much the flaws in the sac weaken the sac so that the strengthening provided by the Precision Profiling process will be known. Now the target abuse cycle test is done with the low cost sealant in place with the clamping mechanism. The clamping mechanism may be strengthening the sac to prevent failures, so a "sac buster" approach may be to make tips with and without the Precision Profiling process and without spray holes, to go into the target abuse cycle test.

$1^{\text {st }}$ Quarter of 2011 Accomplishments: Finished samples of tips of one part number were provided back by the Precision Profiling process supplier that had started with flawed profiles and that then received the specified type of precision profiling process to the target profile. Before and after CT X-ray measurements of these samples showed that the selected precision profiling process naturally focuses on the deviant aspects of the flawed profiles to just remove 
these first, then to machine the entire profile to the desired stock removal. It also showed a natural tendency to blend the sac profile nicely into the spray holes, leaving no cusp (Figure 7).

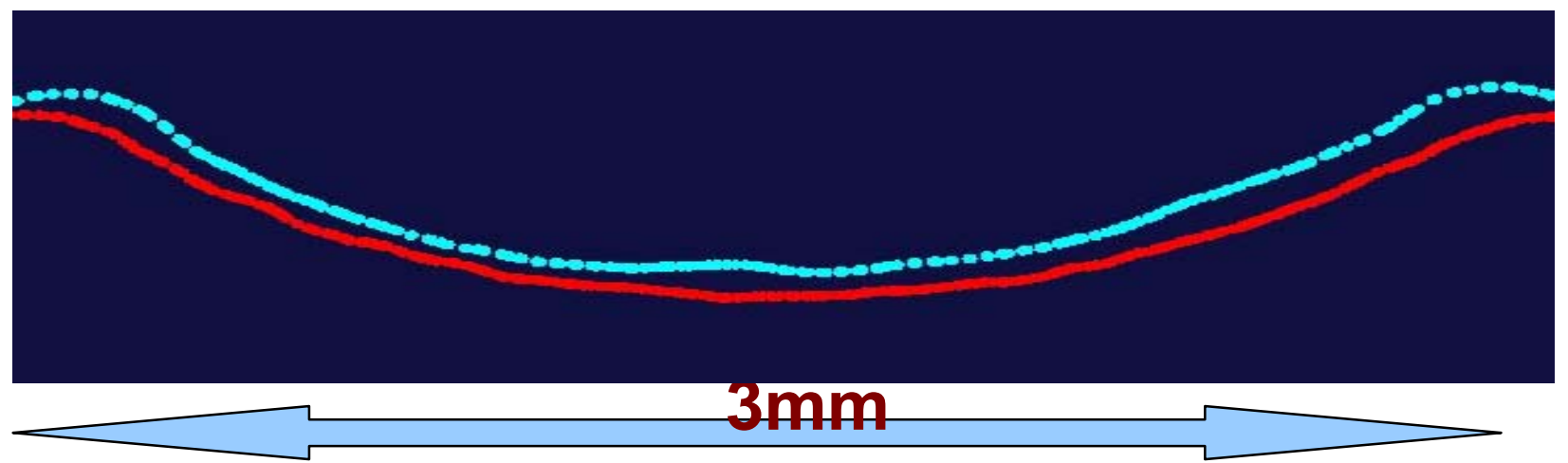

Figure 7. A one-to-one scale of a typical profile showing before the precision profiling process in light blue and after in red, show how the process leaves no witness of the prior profile and leaves a nicely blended radius into adjacent geometries.

Unhardened tips of three part numbers were acquired from Caterpillar Fuel Systems Operations - Manufacturing Engineering/Quality and sent to the precision sac profiling process supplier, without the traditional coining process, according to the preferences expressed by Caterpillar Fuel Systems Operations - Manufacturing Engineering/Quality. These then had stock remaining such that the precision target profile can be imparted to the target position in the tip. The precision profiling process supplier created the remaining tooling to generate the specified sac profiles in these pre-hardened three part numbers.

$1^{\text {st }}$ Quarter 2011 Activities: 1. The UHIP team at this point had target profiles generated in sacs that originally had flawed profiles and from before and after CT X-ray images, it was determined that the selected precision profiling process optimally removes flaws and avoids generation new flaws of its own.

2. The UHIP team was then poised in the $4^{\text {th }}$ project quarter to carry out volume precision profiling on three different part numbers in their soft, pre-hardened state as is the request of Caterpillar Fuel Systems Operations - Manufacturing Engineering/Quality, having process tooling being completed, and volumes of the three part numbers in their soft state shipped to our precision process supplier for process development and validation.

$1^{\text {st }}$ Quarter 2011 Risks, Issues, Concerns: The "sac buster" test using fully finished, hardened tips with and without CRS generation and with and without the Precision Profiling will have to be completed toward the end of the project.

$2^{\text {nd }}$ Quarter 2011 Accomplishments: 50 unhardened tip blanks of three part numbers were sent to the precision sac profiling process supplier, without the traditional coining process, according to the preferences expressed by Caterpillar Fuel Systems Operations Manufacturing Engineering/Quality. These have stock remaining such that the precision target profile can be imparted to the target position in the tip. The precision profiling process supplier created the remaining tooling to generate specified sac profiles in these pre-hardened three part numbers. UHIP team representatives then visited the precision profiling supplier and they demonstrated on three different part numbers of tip blanks that they are able to remove stock and hit the center region of the print profile tolerance and achieve excellent profile to target shape and finish, as required by the project. While the UHIP team representatives were still 
present, they completed the ten pieces of one part number that we desire to CT X-ray before they finish the rest. Ten pieces each of the other two part numbers wear completed when the representatives returned home. The UHIP team was asked by Caterpillar Fuel Systems Product Development if this process could remove the machining flaws and precision form the annular blend between the conical seat and the check bore. Our precision profile process supplier has completed the tooling for this for one part number (the midsize tip) and demonstrated the ability to carry out this process. Boroscope pictures showed that they did smooth and radius this annular area, but only in its lower half. A TRL Review was conducted on the Precision Profiling Process, and it is approved to TRL2.

$2^{\text {nd }}$ Quarter 2011 Activities: 1. The precision profiling process provider completed tooling and received work pieces.

2. The UHIP team have carried out precision profiling of about 15 pieces of each of three different part numbers in their soft, pre-hardened state as is the request of Caterpillar Fuel Systems Operations - Manufacturing Engineering/Quality, having process tooling being completed, and which have been return shipped from our precision process supplier for post process measurement.

3. When we visited the supplier, we were shown how they carry out their process development, how they process the parts and measure their success in profiling. Through all of us as a team working together, we identified the source of one puzzling minor error in their measurement that we can fix in subsequent tips being processed for higher quality results.

4. The post process measurements include boroscopic microscopy pictures and CT X-ray, and these results will be compared to those that were made by the supplier. Other analysis tests will be carried out on these parts, including heat treatment and other standard process steps that can be done, toward completion of a sac-buster test to determine the comparative strength of sacs with and without the precision profiling process.

5. Another internal feature was completed on 10 pieces of one of the part numbers as requested by Caterpillar Fuel Systems - Product Development, because they say this feature has significant flaws out of the form drilling process. They are particularly concerned that this geometry could be as much a source of fatigue failure as is the sac from machining flaws. These surfaces will also be evaluated by CT X-ray and other techniques to evaluate the improvement.

$2^{\text {nd }}$ Quarter 2011 Risks, Issues, Concerns: No new risks, issues or concerns were identified.

$3^{\text {rd }}$ Quarter 2011 Accomplishments: After the process development work that was completed in the $2^{\text {nd }}$ quarter, ten tips of all three part numbers (30 pieces total) were Precision Profiled in the sac region of the unhardened tips and were received back at Caterpillar. These were measured by the molding method at the process supplier, inspected using microscopic boroscope, and where CT X-rayed after the process. CT X-ray measurements were made before they were sent to the Precision Profiling process supplier to be able to be compared before and after the process. The molding results and the microscopic boroscope showed this process had successfully precision profiled the seats. Before and after CT X-ray data had not yet been fully analyzed when it was learned that the CT X-ray digital panel was greatly degraded in its performance. After careful review, the UHIP team decided that the after-process CT X-ray capability with its degraded digital panel was still sufficient to measure the final profile and the amount of material removal, so continued at that time in the analysis process. Ten tips of the midsize tips were precision profiled in the blend area from the check bore into the conical seat, at the request of Caterpillar Fuel Systems - Product Development. The surfaces were imaged with microscopic boroscope and CT X-rayed, analyzed and results were presented at the $61^{\text {st }}$ General Assembly of The International Academy for Production Engineering (CIRP) 
meeting in Budapest, Hungary. The results were not as satisfactory as the sac work, but did show material removal, undilation removal and smoothing.

$3^{\text {rd }}$ Quarter 2011 Activities: 1. Ten pieces for each of three different part numbers were received from the supplier. The supplier still has above 15 pieces for each part number. After process CT X-ray images were completed, they were compared to the pre-measurements.

2. Ten tips of one part number were precision profiled in the annular blend from check bore to precision conical seat. The data shows that the precision profiling only hit the lower half of the blend radius, but it did show this could be done. The region receiving the precision profile showed good finish and profile geometry.

3. The UHIP team reached TRL2 status for the Precision Profiling process.

$3^{\text {rd }}$ Quarter 2011 Risks, Issues, Concerns: The degraded digital panel of the Caterpillar Manufacturing Technology Division CT X-ray made it not capable for the CRS Generation measurements, but after careful consideration and analysis, it was decided it still could make measurements before and after for the Precision Profiling process.

$4^{\text {th }}$ Quarter of 2011 Accomplishments: Ten tips of all three part numbers (30 pieces total) that were precision profiled in the sac region were pre and post process CT X-rayed and the results analysis of the process has been completed. The CT X-ray provided 2D profiles as in Figure 8.
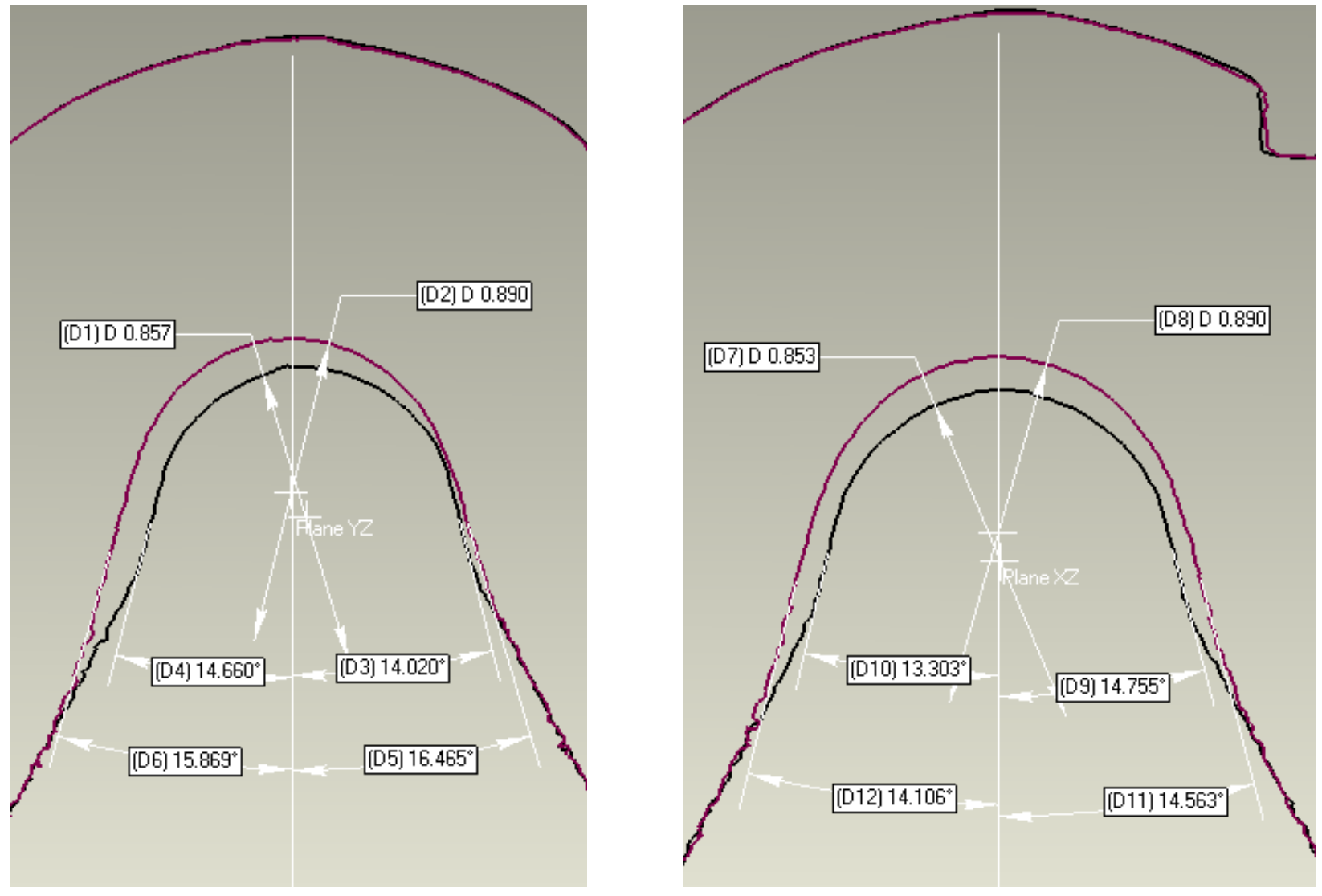

Figure 8. Typical 2D profile information from the CT X-ray measurement of Precision Profiled sac regions of tips. Boxed values are the results of least squares fitting. The black profile is from before the Precision Profiling. The red profile is from after. 
Table 1 shows the least squares results from such 2D profiles. Note that target dimensions were not attained in this run. We asked the Precision Profiling supplier why they did not hit the target dimensions, and they said that they normally process such internal features to remove burrs and edges, and are not driving for a specific dimension. In review of our communication records, we discovered we had not stressed the importance of reaching the final dimensions. Unfortunately, the project period ended before the final Precision Profiling trial could be conducted.

Table 1. Synopsis of CT X-ray least squares results from 2D profiles.

\begin{tabular}{|c|c|c|c|c|}
\hline $\begin{array}{l}\text { Data } \\
\text { Set }\end{array}$ & Feature for each tip type & $\begin{array}{l}\text { Large Size Tip } \\
\text { (value } \pm 3 \sigma)\end{array}$ & $\begin{array}{l}\text { Midsize Tip } \\
\text { (value } \pm 3 \sigma)\end{array}$ & $\begin{array}{l}\text { Small Size Tip } \\
\text { (value } \pm 3 \sigma)\end{array}$ \\
\hline \multirow[t]{4}{*}{1.} & Sac Diameter - Nominal & $1.8+0.05 \mathrm{~mm}$ & $1.06+0.05 \mathrm{~mm}$ & $1.06+0.05 \mathrm{~mm}$ \\
\hline & Before & $1.673 \pm 0.040$ & $0.861 \pm 0.009$ & $0.8635 \pm 0.03$ \\
\hline & After & $1.669 \pm 0.005$ & $0.887 \pm 0.03$ & $0.8765 \pm 0.031$ \\
\hline & Change & $-0.004 \mathrm{~mm}$ & $+0.026 \mathrm{~mm}$ & $+0.013 \mathrm{~mm}$ \\
\hline \multirow[t]{4}{*}{2.} & Sac Center Pos.- Nominal & 0.0 to $0.05 \mathrm{~mm}$ & 0.0 to $0.05 \mathrm{~mm}$ & 0.0 to $0.05 \mathrm{~mm}$ \\
\hline & Before rad.pos.inXYplane & $0.0293 \pm 0.022$ & $0.0323 \pm 0.042$ & $0.0083 \pm 0.030$ \\
\hline & After rad. pos.in $X Y$ plane & $0.0023 \pm 0.009$ & $0.0026 \pm 0.006$ & $0.0025 \pm 0.009$ \\
\hline & Change in Z. & $0.0536 \pm 0.044$ & $0.0602 \pm 0.040$ & $0.0047 \pm 0.050$ \\
\hline \multirow[t]{4}{*}{3.} & Material Removal - Target & $>0.030 \mathrm{~mm}$ & $>0.030 \mathrm{~mm}$ & $>0.030 \mathrm{~mm}$ \\
\hline & Actual & $0.0449 \pm 0.026$ & $0.0722+0.028$ & $0.0109 \pm 0.031$ \\
\hline & By $\Delta$ Center $+\Delta$ Radius & $0.0513 \pm 0.038$ & $0.0775 \pm 0.035$ & $0.0104 \pm 0.040$ \\
\hline & Difference & 0.0076 & 0.0053 & 0.0005 \\
\hline \multirow[t]{4}{*}{4.} & Blend Incl.Angle-Nominal & $20 \pm 2^{\circ}$ & $30 \pm 2^{\circ}$ & $20 \pm 2^{\circ}$ \\
\hline & Before & $18.23 \pm 2.55$ & $28 . \overline{79}+7.08$ & $13.40 \pm 4.58$ \\
\hline & After & $21.88 \pm 2.79$ & $31.37 \pm 3.42$ & $17.12 \pm 5.84$ \\
\hline & Change & +3.65 & +2.58 & +3.72 \\
\hline \multirow[t]{3}{*}{5.} & Cusp Reduction - Target & $<0.020 \mathrm{~mm}$ & $<0.020 \mathrm{~mm}$ & $<0.020 \mathrm{~mm}$ \\
\hline & Before & $0.0605 \pm 0.0203$ & $0.0295 \pm 0.0073$ & $0.0742 \pm 0.0107$ \\
\hline & After & $0.0228 \pm 0.0266$ & $0.0030 \pm 0.0029$ & $0.0397 \pm 0.0078$ \\
\hline \multirow[t]{3}{*}{6.} & Surf. Text.-Target Rz, Wt & $\mathrm{Rz} \leq 0.3 \mu, \mathrm{Wt}<1 \mu$ & $\mathrm{Rz} \leq 0.3 \mu, \mathrm{Wt}<1 \mu$ & $\mathrm{Rz} \leq 0.3 \mu, \mathrm{Wt}<1 \mu$ \\
\hline & Before & Rz 1.143,Wt 4.02 & Rz 1.50, Wt 2.37 & Not available \\
\hline & After & Rz0.221,Wt 0.547 & Rz 0.308,Wt0.399 & Rz0.429,Wt0.333 \\
\hline
\end{tabular}

Note: "Target" means the goal value of this project.

From Data Set 1 in Table 1 we see that for the large size tip, the process did not change the diameter significantly, but rather simply plugged the tool for material removal. The Precision Process supplier said that radius is increased by the dwelling of the tool, but if only plunging is allowed, the internal diameter may not change significantly as is seen here. For the midsize tip, we see that the diameter is increased by 26 microns, when 200 microns was needed to reach the target dimension. Similarly for the small size tips, the diameter was increased by 13 microns when 200 microns was needed. This also showed that the condition we provided to the supplier probably left too much stock for this process. For the next round, we would have supplied tips with at most 70 to 100 microns of stock to be removed, so that a diameter change of 20 to 30 microns could be attained with the single tool. This way only one tool would be needed to both remove the stock necessary and reach the final diameter.

From Table 1, Data Set 2 we see the movement of the center of the sac internal diameter. Overall this shows that the centering of the sac diameter for all three tip types was reduced to 
around two to three microns, down from 30 microns for the large size and midsize tips and eight microns for the small size tip.

Table 1, Data Set 3 shows the material removal at the bottom of the sac (the top of the internal sac diameter in Figure 8). The first value shows the amount of material removed by evaluating the gap from the red profile to the black profile at the sac bottom. The second value is from calculating material removal be evaluating by change in $Z$ position of the internal sphere center, plus the change in radius of the sac internal sphere from the Precision Profiling process. Note that for the large size and midsize tip types, the target material removal levels were obtained (45 microns for the large size and 72 microns for the midsize), but not for the midsize tip type. Also note the two methods of calculating material removal agree to under ten microns, showing that we do understand how the material is being removed.

Data Set 4 shows that for the large size and midsize tips, the process opens up the included angle of the blend cone included angle by about 2.5 to 3.5 degrees, to hit the nominal finished dimension for this feature. For the small size, the included angle is increased by closer to four degrees, but still missed the nominal angle value and tolerance.

Table 1, Data Set 5 shows for the major cusp that is present at the interface between the spherical sac area and the bottom of the blend cone, that the cusp stands proud of the typical profile tolerance 20 microns. For the large and midsize tips, the Precision Profiling process did reduce the cusp from 60 microns down to 20 microns for the large size tips and from 30 microns down to three microns for the midsize tips. For the small size tips, the cusp was reduced significantly, from 74 microns down to 40 microns, but not sufficiently down to the target profile of 20 microns.

Finally, in Table 1, Data Set 6, we see that the surface texture goals are to reduce the Rz (peakto-valley) roughness is to be reduced below 0.3 microns, and the peak-to-valley waviness, $\mathrm{Wt}$, basically the form error in the sac, is to be reduced to under one micron. This Wt is the closest parameter that evaluates the amount of machining damage from the traditional form drilling operation used today. Note again that for the large size and midsize tips, these goals are nicely met. For large size tip the roughness Rz is reduced from 1.14 microns down to 0.22 microns, and the waviness $\mathrm{Wt}$ is reduced from four microns down to 0.55 microns. For the midsize tips, the roughness $\mathrm{Rz}$ is reduced from 1.5 microns down to 0.3 microns, while the waviness $\mathrm{Wt}$ is reduced from 2.4 microns down to 0.4 microns. But for the small size tip we were not able to measure the pre machined state as the internal molding process carried out at the Precision Profiling process supplier was never was able to result in good impressions of the sac regions (they always resulted in voids in that area). But here at Caterpillar Manufacturing Technology Division we were able to gain good impressions of the finished, after process parts, and these showed the Rz finish at 0.4 microns, and the Wt form error at 0.3 microns.

The data showed that the UHIP team fully understands the precision profiling process and that it provides the type of modification to interior surfaces of the sac and the sac/seat blending geometries that is needed. It also showed that measurements with the degraded CT X-ray detection panel were sufficient for this work. TRL3 was attained for this precision profiling work based on these results, because they do depict that the process is capable, even though targets were not met in all cases. Future plans are to take this process to greater capability in 2012, to reach good final print dimensions, geometry and finish, with good elimination of surface flaws and cusps that could act like fracture and failure initiation sites at high injection pressure. 
$4^{\text {th }}$ Quarter 2011 Activities: 1. Ten pieces for each of three different part numbers were received from the supplier with our specified internal surfaces precision machined. All CT X-ray images have been acquired, and full analysis of the CT X-ray data is complete. The analysis showed the process eliminated flaws and profile cusps completely with the capability to remove material to reach the specified profile (see Figure 8).

2. Ten tips of one part number were precision profiled in the annular blend from check bore to precision conical seat. The CT X-ray analysis showed the process eliminated flaws and profile cusps completely with the capability to remove material to reach the specified profile. The precision profiled region showed finish and profile geometry well within the needed tolerances.

3. The UHIP team at this point attained TRL3 status with this process.

$4^{\text {th }}$ Quarter 2011 Risks, Issues, Concerns: It had been decided, at the suggestion of Caterpillar Fuel Systems - Product Development, to use three high volume current production part number tips to develop the Precision Profiling process. This was because the target part number tip was undergoing continued design changes. It was anticipated that there would not be sufficient quantity of samples to do the Precision Profiling process development, because there was barely sufficient quantity of sample tips to carry out the CRS Generation process development. But the tooling for the high pressure, high cycle abuse test had only been designed and fabricated for the CRS Generation process development on this target tip design that was still under design change.

But toward the end of the project, in order to develop the sac buster test development on the tips that were Precision Profiled, completely new high cycle, high pressure abuse test tooling would have to be developed. This means that the fatigue and performance testing will be very difficult to complete, requiring long delays in obtaining the necessary tooling and having these tips gain test time on the fatigue and performance test rigs. So for these reasons it was decided the testing in Subtask 5.3 would not be completed fully by the end of the project.

\section{Completion of Statement of Project Objective (SOPO) Tasks and Subtasks for the Precision Profiling Process}

Task 5 Precision sac profiling process development is 100\% complete and TRL3 was attained on the precision profiling process. Our target precision sac profiling process supplier has completed about 100 tips, with their analysis finished. The analysis results reveal that the process removes sac flaws with excellent efficiency and with no witness of the flaw geometry left. CT X-ray analysis is completed, and results will be included in the final report.

Subtask 5.1 The initial process trials are $100 \%$ successfully complete.

Subtask 5.2 The precision profiling process supplier has machined the 150 unhardened, Fuel System machined soft blanks, for three part numbers (50 each). They have developed the process and machined the first ten of each that are well within expected tolerances, as measured with their impression molding method. Our CT X-ray measurements and analysis verified their results. These results were contained in reports used to justify the attainment of TRL3 status, so this Subtask is $100 \%$ complete.

Subtask 5.3 This task will plan to develop the sac-buster test to carry out this work that will involve fatigue testing the precision profiled sac tips in the fatigue tester, comparing them with the fatigue testing of standard machined profiled tips. This Subtask is at a $50 \%$ complete level.

It had been decided, at the suggestion of Caterpillar Fuel Systems - Product Development, to use three high volume current production part number tips to develop the Precision Profiling process. This was because the target part number tip was undergoing continued design changes. It was anticipated that there would not be sufficient quantity of samples to do the 
Precision Profiling process development because there was barely sufficient quantity of sample tips to carry out the CRS Generation process development. However, tooling for the high pressure, high cycle abuse test had only been designed and fabricated for the CRS Generation process development on this target tip design that was still under design change. In order to develop the sac buster test development on the tips that were Precision Profiled, completely new high cycle, high pressure abuse test tooling would have to be developed. This means that the fatigue and performance testing will be very difficult to complete, requiring long delays in obtaining the necessary tooling and having these tips gain test time on the fatigue and performance test rigs. So for these reasons Subtask 5.3 to perform this test will not be completed fully by the end of the project. It was in the last two months of the project when we realized this situation existed.

Task 6 Precision sac profiling process capability (Cpk), and volume and cost capabilities development toward a production process is $100 \%$ complete and TRL3 status was attained. The supplier has processed 100 tips using a production-type of process, for which we have CT X-ray measurements and final analysis computed on a statistically valid sample of parts.

Subtask 6.1 The supplier has provided tips that they know are well within the specified profile tolerance with low profile deviations from the current print profile tolerance, and the process they used is very much like the production process which has been evaluated for Cpk and production rates. Therefore, this Subtask is $100 \%$ complete.

Subtask 6.2 The CT X-ray metrology has demonstrated the ability to resolve the quality of the precision profiling process. We completed the CT X-ray measurements and analysis on the 30 tips we have, and have developed a plan for using this method for SPC. Thus, this step is at a $100 \%$ completion level.

\section{7c. For the CT X-ray dimensional control of the Precision Profiling process and the CRS (Compressive Residual Stress) Generation control of the CRS Generation process -}

$4^{\text {th }}$ Quarter 2010 Accomplishments: Many of the pre-measurements for Precision Profiling process and the CRS Generation process were made before process trials, but the CT X-ray went down in early December which halted progress at a time when the UHIP team was beginning the fine work of testing to push the capability of our CT X-ray capability. The failure was in the power supply for the X-ray tube. Out of the CRS Generation process and Precision Profiling process work we had at this point a number of parts that had been pre-CT X-rayed and were now awaiting post-CT X-ray to determine the change that can be seen, so at the end of the $4^{\text {th }}$ quarter this work was eminent.

$4^{\text {th }}$ Quarter 2010 Risks, Issues, Concerns: 1 . It was seen that the machine would be coming up soon, after being down with a failed X-ray tube power supply for a couple of months, and the UHIP team at that point needed to negotiate with the customer list for the machine to place UHIP projects on high priority to catch up.

2. The UHIP team needed to make sure the calibration of the CT X-ray is completed and monitored meticulously so that before and after measurements that are seeking to resolve a few microns of surface change can be completed with reliable results.

$1^{\text {st }}$ Quarter 2011 Accomplishments: The CRS Generation process supplier only in later February had the power supply repaired and back in the US. This was a very frustrating experience and caused us to have less trust in the service arm of the CRS Generation process supplier. The UHIP team felt then focus could be on this capability development this year and catch up in $4^{\text {th }}$ quarter of the project. CT X-ray measurements done before and after the CRS generation showed that CT X-ray can clearly resolve the surface movement from this process, 
which amounts to measuring the strain imparted to the process. Various degrees of CRS generation also showed various degrees of strain by the CT X-ray measurement process. CT X-rays measurements completed before and after the precision profiling process showed ability to see fine profile improvement of this machining approach, to show that the process removes the deviations, leaving no residual witness of the profile deviations after the process. Caterpillar Fuel Systems Operations - Manufacturing Engineering/Quality received their CT X-ray in Pontiac, Illinois which then was being installed and developed to be in their work flow to better control their traditional processes.

$1^{\text {st }}$ Quarter 2011 Risks, Issues, Concerns: 1 . The UHIP team have discovered that the CT Xray machine might be affected by the temperature of the room it is located in, especially if measurements are being made during the time of year when regular office air conditioning is turned off. The procedure was instituted then to begin calibrating three times a day: morning, noon and evening.

2. The UHIP team needed to make sure the calibration of the CT X-ray is completed and monitored meticulously so that before and after measurements that are seeking to resolve a few microns of surface change can be completed with reliable results.

3. In the $4^{\text {th }}$ quarter the UHIP team will perform a measurement systems analysis or gage repeatability and reproducibility (GR\&R) study to determine the standard deviation of the CT Xray process.

$2^{\text {nd }}$ Quarter of 2011 Accomplishments: CT X-ray measurements done before and after the CRS generation continued to show that CT X-ray can clearly resolve the surface movement from this process, which amounts to measuring the strain imparted to the process. Various degrees of CRS generation continued to show various degrees of strain by the CT X-ray measurement process.

CT X-ray completed before and after the precision profiling process continued to show ability to see fine profile improvement of this precision machining approach, showing that the process removes the deviations, leaving no residual witness of the profile deviations after the process.

The UHIP team also showed that the CT X-ray can measure the amount of CRS that has been applied above the tip sac interior and also to the seat area. Caterpillar Fuel Systems Operations - Manufacturing Engineering/Quality has a CT X-ray now in full use to better control their traditional processes. The overall CT X-ray measurement process is approved at TRL4 so far. This project was seen to be a major contributor to the progression of the capability of the CT X-ray, and to the influence of Caterpillar Fuel Systems Operations - Manufacturing Engineering/Quality to convince them of the capability of this powerful measurement and analysis tool.

$2^{\text {nd }}$ Quarter 2011 Risks, Issues, Concerns: 1. The UHIP team continued to need to make sure the calibration of the CT X-ray is completed and monitored meticulously so that before and after measurements that are seeking to resolve a few microns of surface change can be completed with reliable results.

2. Final analysis of the last 50 tips with CRS generation in 3Q2011 will include a measurement systems analysis study (MSA or GR\&R study) to calculate the CT X-ray standard deviation.

$3^{\text {rd }}$ Quarter of 2011 Accomplishments: For CT X-ray of CRS generation, using before and after CRS generation CT X-ray measurements, the results were not good. Further analysis showed our CT X-ray digital panel was decayed to the point that it could no longer make good measurements (within the necessary minimal micron uncertainty band). All final analysis work were delayed by this unexpected development. The UHIP team then began a process to 
acquire another digital panel for the machine. Since the cost is around $\$ 80 \mathrm{~K}$, it could not happen quickly as the UHIP team had to find an unplanned budget area within the Caterpillar Product Development and Global Technologies Division budget with which to fund it. In the mean time, the UHIP team gained approval to have the FS Mfg. Plant in Pontiac redo the after CRS generation measurements using their newer CT X-ray, following our careful calibration and accuracy checking process. Results were expected to be completed in 4Q2011. For precision sac profiling it was decided that even with the degraded digital panel, that the CT X-ray measurements could be used. Analysis even on the Precision Profiling process were also delayed due to time lost determining how to proceed.

$3^{\text {rd }}$ Quarter 2011 Risks, Issues, Concerns: 1. The UHIP team have discovered that the digital panel on the CT X-ray has a finite life. Ours is now not able to perform fine measurement in about three years of medium to heavy use. The purchase process for a longer life replacement was set in motion, and it was noted that monitoring for digital panel degradation after $40 \%$ life is warranted.

$4^{\text {th }}$ Quarter of 2011 Accomplishments: For CT X-ray of CRS generation, using before and after CRS generation CT X-ray measurements, with the after measurements being completed on the newer Caterpillar Fuel Systems Operations - Manufacturing Engineering/Quality machine, the results for the presence of CRS were excellent. This demonstrated to the UHIP team that the calibration, calibration checking and accuracy validation methodology under use provides much greater flexibility in where and when measurements are completed to analyze a fuel system's precision manufacturing process currently under development.

For precision sac profiling, the full analysis on the CT X-ray before and after measurements was completed and the results proved to be outstanding, with good self correlation, to reveal what was happening in this process. So the UHIP team's decision was to proceed using the data from our degraded X-ray digital panel proved to be correct. The analysis was used to attain TRL3 status. Another CT X-ray digital panel was acquired (using Caterpillar capital funds), installed and brought to full operation, restoring our Caterpillar Technical Center CT X-ray back to full capability.

One requirement to attain TRL3 status was to determine the repeatability or uncertainty of this CT X-ray measurement method. From measuring the 40 pieces for the CRS generation process twice before and twice afterward, we were able to carry out such evaluations. We did perform a Measurement Systems Analysis (MSA) of the CT X-ray measurement capability to measure spray hole diameters by using the two measures before the CRS generation and the two measures after. We used the standard MSA procedure from the Automotive Industry Action Group (AIAG) to carry out the estimation. This study showed that the $6 \sigma$ spread for measuring such spray holes consumes about $35 \%$ our surface movement tolerance.

We also performed an MSA of the capability of the CT X-ray to measure surface movement due to the CRS generation process. We found from the 40 pieces measured two times before CRS generation and two times afterward, that this surface movement process $6 \sigma$ spread consumes about $49.7 \%$ of our expected surface movement tolerance. It was also noted that all the data taken on these pieces (80 measurements) shows that the $6 \sigma \mathrm{Cp}$ of the total process (surface movement plus the measurement error) consumes about $64.65 \%$ of our desired surface movement band. From this, the estimated $6 \sigma$ process width without the measurement width consumes about $41.4 \%$ of the desired band of surface movement, using standard root mean square arithmetic. Then using the total process $6 \sigma$ width (from both surface movement width plus measurement width) in a Cpk calculation, we see that the process has a Cpk of 1.23, which 
is an acceptable value. So we can say that we can monitor the CRS generation process parameters, and monitor the total process Cpk, and if the process parameters stay above targets and within windows, and this Cpk stays appreciably above one, then we can be confident of our quality. In completing this analysis, the UHIP team found the uncertainty to be right at the needed uncertainty level that was previously expected, and that the CT X-ray can be an effective tool to target the CRS generation process and monitor its capability.

$4^{\text {th }}$ Quarter 2011 Risks, Issues, Concerns: 1. Final analysis of the last 40 tips with CRS generation has included a measurement systems analysis study (MSA or GR\&R study) to calculate the CT X-ray standard deviation, showing the CT X-ray process is capable to the needed small uncertainty across a $6 \sigma$ spread of values.

2. We have discovered that the digital panel on the CT X-ray has a finite life. The results of this study revealed that fine measurements could not be performed after approximately three years of medium to heavy use. A new longer life replacement has been purchased by Caterpillar and installed, and the UHIP team anticipates monitoring its performance after $40 \%$ life is warranted.

Completion of Statement of Project Objective (SOPO) Tasks and Subtasks for a NonDestructive Measurement Technique for the CRS Generation Process and the Precision Profiling Process.

Task 1.0 Development of Non-Destructive CRS Metrology is 100\% complete: The UHIP team have performed a full uncertainty analysis and found the functional uncertainty of the level of CT X-ray that we have is able to measure surface movement to the needed uncertainty level. Attaining TRL3 status confirmed that CRS can be seen in surface movement of geometries above the sac region, with full confidence that there are no anomalies. We also achieved a level of certainty that we can resolve such surface movement in several types of geometries in the before and after CT X-ray measurements. The data also assured with careful calibration, and repeated calibrations, even when the environment has thermal drift, measurements can be relied upon to show that we have successfully imparted the CRS.

\section{Completion of Statement of Project Objective (SOPO) Tasks and Subtasks for UHIP Project Reporting}

Tasks 7\& 8 All project tasks with the exception of Subtask 5.3 as earlier explained, are $100 \%$ complete, as set forth in this Final Technical Report.

\section{BENEFITS ASSESSMENT - POTENTIAL ENERGY, ECONOMIC, ENVIRONMENTAL, MARKET BENEFITS:}

UHIP Technology potential energy consumption reduction: This UHPCR fuel system is targeted for implementation on Caterpillar engines that have rated horsepower from $750 \mathrm{HP}$ to $3200 \mathrm{HP}$ to bring these engines to US EPA Tier 4 Final emissions levels. The system is designed to be scalable to engine horsepower for engines in this power range. The demonstrated fuel savings is $2.4 \%$ over Tier 4 Interim. We calculate that when the accumulation of these engines in the field begin to plateau in volumes, that the energy savings will be in the 0.2 to 0.3 Quads/year range (200 to 300 Trillion BTU/yr). Assumptions are:

- The average brake specific fuel consumption (BSFC) is around $3.00 \mathrm{lbs} / \mathrm{hp}-\mathrm{hr}$,

- We use Caterpillar Marketing projections of number of engines sold per year of each per cylinder displacement and horsepower per cylinder to calculate the total volume of horsepower projected to be sold each year,

- We then look at the applications of these engines and estimate the average duty cycle 
(number of hours per year) of this total horsepower, running the numbers for average use of 2000 hours to 3000 hours/ yr. Then from this determine the accumulated volume of horse power in the field each year using the UHPCR fuel system after 2013,

- We use the $2.4 \%$ of fuel savings demonstrated by the prototype results.

The calculation of trillion BTUs of fuel saved is by use of the following equation:

\section{Savings $=(\#$ cyl/yr)(liters/cyl)(ave.hp/liter)(BSFC)(2.4\% savings)(\#2 diesel gal./lb) $x$ (hrs/yr engine running at rated)(\#2 diesel trillion BTU/gal)}

Based on Caterpillar market projections, Table 2 shows the estimated savings from accumulated Tier 4 Final engines in operation by year would be as follows (in trillions BTU/yr):

Table 2. Estimated Energy Savings from accumulated Tier4 Final engines running w/UHIP

\begin{tabular}{|l|l|l|l|l|l|l|l|l|}
\hline Year & 2013 & 2014 & 2015 & 2016 & 2017 & 2018 & 2019 & 2020 \\
\hline Projected 2000hrs/yr savings & 1.50 & 3.04 & 21.3 & 50.5 & 97.8 & 157.9 & 223.4 & 261.4 \\
\hline Projected 3000hrs/yr savings & 2.21 & 4.56 & 32.0 & 75.7 & 142.2 & 204.8 & 264.0 & 277.4 \\
\hline
\end{tabular}

This is a conservative estimate because this system is actually scalable down to $200 \mathrm{HP}$ engines, so that the UHPCR should show benefit for engines from $200 \mathrm{HP}$ to $700 \mathrm{HP}$, probably to the level of at least $30 \%$ and possibly as high as $50 \%$ of these engines in this time interval. We also ran the numbers for saving the production and addition of the exhaust after-treatment, but this came out to be negligible in quads compared to the fuel consumption savings. Also there is a fuel economy loss on moving machines to carry around the after-treatment system, which averages about $50 \mathrm{lb} / \mathrm{liter}$ added weight to the vehicle ${ }^{1}$. These considerations show that the 0.2 to 0.3 quad/year savings is, in all probability, a conservative estimate.

\section{UHIP technology to reduce greenhouse gas and other environmental pollutant emissions, as compared to the technology currently in commercial use (such as those that are Tier 4 Interim compliant).}

This system will eliminate the need for fine-mesh style diesel particulate traps (DPTs) such as would be used in normal full scale after-treatment. This will enable broader use of biodiesels which cause problems for current technology DPTs, due to there higher levels of oxidation. They tend to load up these fine-mesh style DPTs, causing excessive exhaust back pressure and DPT failure. The National Biodiesel Board website ${ }^{2}$ reports, "A 1998 biodiesel lifecycle study, jointly sponsored by the US Department of Energy and the US Department of Agriculture ${ }^{3}$ concluded biodiesel reduces net $\mathrm{CO}_{2}$ emissions by 78 percent compared to petroleum diesel. This is due to biodiesel's closed carbon cycle. The $\mathrm{CO}_{2}$ released into the atmosphere when biodiesel is burned is recycled by growing plants, which are later processed into fuel." Also it states, "A U.S. Department of Agriculture (USDA) and Department of Energy (DOE) study has already shown that soy-based biodiesel has a $78 \% \mathrm{CO}_{2}$ reduction. This study takes into account everything from planting the soybeans to delivering biodiesel to the pump. Furthermore, for every gallon of B100 that is consumed, ...Greenhouse Gas Emissions ... (are reduced)... by 16.12 pounds. A fleet that uses 1,000 gallons of $\mathrm{B} 100$ per year generates $\mathrm{CO}_{2}$ emission reductions equivalent to removing 1.4 cars from our roadways. These numbers become even more extraordinary when ...(considering)... the overall benefit on a national scope both in terms of tonnage of $\mathrm{CO}_{2}$ reductions and vehicle equivalents. In 2007 alone, biodiesel's contribution to reducing greenhouse gas emissions was equal to removing 700,000 passenger vehicles from America's roadways, and decreasing $\mathrm{CO}_{2}$ by 8.06 billion pounds." Through-flow DPT's will not be effected by burning even high percentages of current biodiesel fuels. 
The potential economic benefits of the proposed technology over current technology: The UHPCR has potential economic benefits in several areas:

- It enables the full use of biodiesel fuel, the production of which will create US jobs and reduce foreign oil dependence.

- It will eliminate the need for fine-mesh DPT's and either the cooled exhaust gas recirculation (CEGR) system or the SCR NOx reduction after-treatment which will greatly reduce the cost of after-treatment on engines using it, giving them competitive pricing to competitive engines.

- It provides a $2.4 \%$ fuel economy over alternative combustion and after-treatment approaches, that will save the user, and the nation on fuel consumption.

9. COMMERCIALIZATION - Discussion of the potential markets that would be impacted by successful development and commercial implementation of the proposed technology:

The primary target for this UHPCR are the high horsepower engines ranging from $750 \mathrm{HP}$ to $3200 \mathrm{HP}$ that go into the following markets listed with the average annual use in that market, as shown in Table 3:

Table 3. Annual hours of Caterpillar engine use for most engine applications

\begin{tabular}{|l|l|}
\hline Market & Average Annual Hours of Use for the Market \\
\hline Oil Field & 2000 \\
\hline Construction & 1500 \\
\hline Mining & 6000 \\
\hline Passenger Marine & 2000 \\
\hline Luxury Marine & $<500$ \\
\hline Commercial Marine & 4000 \\
\hline Forestry & 4000 \\
\hline Prime Power & 6000 \\
\hline Standby Power & $<500$ \\
\hline
\end{tabular}

Caterpillar Global Mining, Caterpillar Electric Power, and Caterpillar Marine Power Systems have all relayed to Caterpillar Large Power Systems Division that they cannot accept a massive after-treatment add-on system into their engine compartments or into the applications where they use these engines. They will only accept a Tier 4 Final solution that makes use of a minor after-treatment add-on. This has been a primary motivator for Caterpillar Fuel Systems Product Development to develop the UHPCR fuel system. So what ever company successfully provides this type of system that scales down the size and mass of the emissions hardware for this entire power range has the opportunity to dominate that market.

Alternate fuel enabling impact from UHIP technology: The technology will also impact the biodiesel market by enabling broader use of B100 fuel due to the low level of after-treatment required and the avoidance of the use of fine-mesh DPT's that tend to plug and fail when B100 is used. This will create agricultural jobs and domestic products, and infrastructure jobs and domestic products at an estimated rate of 10,000 to 25,000 jobs per $\$ 1 \mathrm{~B}$ less crude oil importation (estimates from the National Biodiesel Board) ${ }^{2}$.

These engines and the machines they power are also, by this advanced fuel system technology, enabled to burn fuels (biodiesels) that have the potential to provide an $80 \%$ reduction in net GHG emissions over burning No.2 diesel from fossil fuels. The use of biodiesel also dramatically reduces the US consumption of foreign oil, while burning $2.4 \%$ less fuel overall. 
Table 4 provides the National Biodiesel Board has released the following production volume estimates for the US.

Table 4. US Biodiesel Production Volume Estimates

\begin{tabular}{|l|r|}
\hline Fiscal Year & Est. Biodiesel Gallons Produced \\
\hline 1999 & 500,000 \\
\hline 2000 & $2,000,000$ \\
\hline 2001 & $5,000,000$ \\
\hline 2002 & $15,000,000$ \\
\hline 2003 & $20,000,000$ \\
\hline 2004 & $25,000,000$ \\
\hline 2005 & $75,000,000$ \\
\hline 2006 & $250,000,000$ \\
\hline 2007 & $450,000,000$ \\
\hline 2008 & $700,000,000$ \\
\hline 2011 & $2,000,000,000$ \\
\hline
\end{tabular}

Source: The National Biodiesel Board ${ }^{2}$

For every billion dollars spent on foreign oil, America lost 10,000 to 25,000 jobs. The 700 million gallons in 2008 were produced from about 20 million barrels of crude, which were bought for $\$ 60$ per barrel. So the US stopped the purchase of $20 \mathrm{~B}$ barrels of foreign crude in 2008 with this level of biodiesel production and use, which crude oil on the current commodity market is going for around $\$ 60$ per barrel, saving $\$ 1.2 \mathrm{~B}$ in foreign crude oil purchased, and therefore saved 10,000 to 15,000 jobs. Biodiesel also has a positive energy balance. For every unit of energy needed to produce a gallon of biodiesel, 3.24 units of energy are gained. Since diesel from foreign crude oil has a negative energy balance of .88 , every gallon of biodiesel used has the potential to extend US petroleum reserves by four gallons. Because these engines offer $2.4 \%$ lower fuel consumption, and have around $25 \%$ lower cost by eliminating the complex after-treatment module, they will be widely and enthusiastically accepted in the market place. They will give the end user the ability to generate more power with less space consumption, with lower fuel consumption, lower overall initial cost, lower overall weight of the engine, greater ability to use renewable, low GHG fuels, and reduce US dependency on foreign oils. Because of all these advantages, we believe engines with the UHPCR fuel system will be greatly accepted in the high horse power engine market.

\section{CONCLUSIONS AND RECOMMENDATIONS - for the results of this Project:}

Conclusions: For the CRS Generation process, the UHIP Team and it's Caterpillar customers, Caterpillar Fuel Systems - Product Development and Caterpillar Energy and Power Systems Research are at the conclusion that this process is fully capable, is ready to be installed on Caterpillar high injection pressure fuel systems, and is ready to develop toward full production. It is now being incorporated into future engine product plans for Caterpillar.

For the Precision Profiling process, the UHIP team sees that it can effectively and capably alleviate the flaws in the sac region for greater strength of the sac to high pressure injection. If Caterpillar decides to have a product that uses ultrahigh injection pressures, even greater than the UHIP Team ever envisioned, then combining the CRS Generation process and the Precision Profiling process into such a product would be called for and therefore proposed by 
the Caterpillar Manufacturing Technology Division. Also in the process of exploring this processes capability, it was learned that it also has other possibilities to precision machine tip features at the same time as it Precision Profiles the sac region, and this is being explored in continued process development in 2012.

The CT X-ray capability has been invaluable to this entire development, and other machines are being proposed and acquired within Caterpillar, in large part due to the success it has had for this project. We pushed the CT X-ray capability to its limits and showed it has the capability for dimensional control to levels required to measure minute surface changes that are vital to UHIP fuel system performance.

Recommendations: It is recommended that the CRS Generation and the Precision Profiling processes be considered for implementation in order to have more robust, lower cost, more fuel efficient and fuel versatile engines that meet US EPA Tier 4 Final emission regulations for offhighway equipment. Clearly only one component, the injector tip was worked on in this project, but the technology needs to be replicated across all fuel systems components that will be operating at UHIP levels and beyond in order to realize these benefits for future EPA Tier 4 Final engine products. Thus future work needs to study how these processes can be used to benefit a wider range of UHIP exposed components, and what it takes to implement these processes into high volume production. We also need to use the UHIP capability to work on alternate fuels and the less refined fuels found in lesser regulated countries, to broaden the customer base with low emissions to include a more global impact.

\section{REFERENCES:}

1. "Operational Evaluation of Emissions and Fuel Use of B20 Versus Diesel Fueled Dump Trucks", H.C.Frey and K.W. Kim, North Carolina State University Dept. of Civil, Construction and Environmental Engineering, September, 2005.

2. National Biodiesel Board Report website, www.nbb.org.

3. "Life Cycle Inventory of Biodiesel and Petroleum Diesel for Use in an Urban Bus", J.Sheehan, V.Camobreco, J.Duffield, M.Graboski, H.Shapouri, Sponsored by the USDoE Office of Fuels Development and the USDoA Office of Energy, National Renewable Energy Laboratory, Golden, CO, May, 1998 